Received 00th January 20xx, Accepted 00th January 20xx DOI: $10.1039 / x 0 x \times 00000 x$

\title{
Record power conversion efficiencies for Iron (II)-NHC-sensitized DSSCs from rational molecular engineering and electrolyte optimization
}

\author{
Anil Reddy-Marri, ${ }^{\text {a }}$ Edoardo Marchini, ${ }^{\text {b }}$ Valentin Diez Cabanes, ${ }^{\mathrm{c}}$ Roberto Argazzi, ${ }^{\mathrm{d}}$ Mariachiara \\ Pastore, ${ }^{{ }^{c}}$ Stefano Caramori, ${ }^{* b}$ and Philippe C. Gros, ${ }^{*^{a}}$
}

\begin{abstract}
Three Fe(II) pyridyINHC-carboxylic heteroleptic complexes with (ARM7 and ARM11) or without spacers (ARM13) between the pyridine and the $\mathrm{COOH}$ anchoring group have been designed and characterized with the aim to increase the metal to surface charge separation and avoid undesired recombination processes in iron-sensitized DSCCs. ARM13-sensitized DSSC scored the highest efficiency ever reported for an iron-sensitized solar cell (1.44\%) providing that $\mathrm{Mg}^{2+}$ cations and $\mathrm{NBu}_{4} \mathrm{I}$ were present in the electrolyte thus substantially boosting the photocurrent. The gain in efficiency derived from the use of $\mathrm{MgI}_{2}$-based electrolytes was rationalized by employing DFT calculations of the isolated dye sensitizers and dye/ $/ \mathrm{TiO}_{2}$ interface models.
\end{abstract}

\section{Introduction}

Dye sensitized solar cells are one of the prominent and less expensive alternative to conventional silicon based solar cells. ${ }^{1-3}$ Since, the first breakthrough achieved by Grätzel and co-workers with more than $10 \%$ efficiency by utilizing the classical ruthenium complex $\mathbf{N} 3$ and its doubly-deprotonated analogue $\mathbf{N 7 1 9 ,}{ }^{4}$ numerous sensitizers have been developed by replacing one of the dicarboxybipyridine from N3 with 4,4' functionalized bipyridines for improved light harvesting as well as device stability. ${ }^{5-11}$ Till date, the highest efficiency $13 \%$ has been achieved by Grätzel group using panchromatic dyes with cobalt based electrolytes. ${ }^{12}$ The large device efficiencies achieved by $\mathrm{Ru}$ (II) complexes have been ascribed to the long lifetime of their metal to ligand charge transfer (MLCT) lowest excited states (which is in the orders of few ns), and the efficient electron-hole pair separation induced by their particular absorption geometry, which is hampering the charge recombination processes at the dye/semiconductor interface. ${ }^{13-15}$ However, the large-scale production of these ruthenium complexes is jeopardized by their high cost, tricky purifications, and environmental issues.

Given the scarcity of ruthenium, researchers have focussed

\footnotetext{
a. Université de Lorraine, CNRS, L2CM, F-54000 Nancy

e-mail : philippe.gros@univ-lorraine.fr

b. Department of Chemical and Pharmaceutical Sciences, University of Ferrara, Via L.Borsari 46, 44121, Ferrara, Italy

e-mail: cte@unife.it

c. Université de Lorraine, CNRS, LPCT, F-54000 Nancy

e-mail : mariachiara.pastore@univ-lorraine.fr

d. CNR-ISOF C/O Department of Chemical and Pharmaceutical Sciences, University of Ferrara, Via L.Borsari 46, 44121, Ferrara, Italy
}

Electronic Supplementary Information (ESI) available: [copies of compounds NMR spectra, additional computational and photovoltaic data]. See DOI: $10.1039 / x 0 x \times 00000 x$ attention on moving to low-cost earth abundant first row

transition metal complexes as sensitizers ${ }^{16,17}$ or metal-free organic sensitizers. ${ }^{18-20}$ The first-row transition metal sensitizer $\mathrm{Fe}(\mathrm{dcbpy})_{2}(\mathrm{CN})_{2}$ (F2CA), was first introduced by Ferrere and Gregg. ${ }^{21,22}$ Its poor efficiency in DSSC was recently improved by McCusker and co-workers reporting $0.35 \%$ efficiency using the F2CA complex by optimizing the electrolyte composition. ${ }^{23}$ In general, in order to obtain high quantum injection yields, the MLCT excited state lifetime should be orders of magnitude larger with respect the injection rates. For that reason, iron (II) polypyridyl sensitizers are inefficient for solar cell applications due to their too short lived MLCT excited state lifetimes (100 fs) ${ }^{24}$ arising from ultrafast deactivation by population of the low lying metal-centred (MC) states thus annihilating the suitable photophysical properties. Notable advances have been recently reported by our group and others using pyridyl$\mathrm{N}$-heterocyclic carbenes ( $\mathrm{NHC}$ ), due to the increase in the ligand donor strength, which stabilizes the MLCT sates with respect to the $\mathrm{MC}$ ones. ${ }^{25-31}$ This strategy has allowed iron complexes to reach MLCT state lifetimes up to the picosecond $^{28,32-34}$ and nanosecond ${ }^{35}$ scales. One illustrative example of these NHC dyes is the iron complex C1 (Fig. 1) which combines s-donating NHCs ligands (showing MLCT lifetimes up to $16 \mathrm{ps}$ ) with p-accepting carboxylic groups for grafting to the $\mathrm{TiO}_{2}$ surface. ${ }^{26}$ Despite its relatively long lifetime, however, C1 displayed very poor photovoltaic performances, that were shown to be linked to the fast recombination of the oxidized dye with the electrolyte, ${ }^{36}$ and to a low injection efficiency due to the wrong direction of the charge flow in the lowest MLCT states of the homoleptic compounds. ${ }^{30} \mathrm{Ab}$ initio calculations of the $\mathrm{C} 1 / \mathrm{TiO}_{2}$ electronic structure and of interfacial electron injection rates, indeed, 
revealed that, once anchored on the $\mathrm{TiO}_{2}$ substrate, the lowest-energy MLCT state promotes charge transfer from the metal to the not-anchored NHC ligand, thus resulting in a quenched electron injection. A rather tilted adsorption geometry of the dye on the semiconductor, yielding a close distance between the surface and the oxidized dye, also suggested possible fast back recombination reactions. ${ }^{30}$ These findings clearly gave us two fundamental guidelines in the search of higher-efficient Iron-based sensitizers: moving to heteroleptic complexes to guarantee the desired dye-to- $\mathrm{TiO}_{2}$ electron flow and possibly increasing the distance between the oxidized metal centre and the $\mathrm{TiO}_{2}$ substrate to slow-down back recombination processes. Very recently, however, some of us reported that C1-based DSSCs efficiency can be boosted up to $1 \%$ by means of $\mathrm{Mg}^{2+}$ cations in the electrolyte, ${ }^{36}$ with a remarkable increase in the photocurrent value from 0.4 to 3.3 $\mathrm{mA} / \mathrm{cm}^{2}$. This indicated that $\mathrm{Mg}^{2+}$ cations, capable to adsorb at the molecule/semiconductor interface, even reducing the $V o c$ by downshifting the $\mathrm{TiO}_{2}$ conducting band (CB), can notably improve the interfacial electron transfer kinetics (regeneration and/or electron injection), resulting in higher measured photocurrents.

With this knowledge in hand, here we report three heteroleptic complexes (Figure 1): one of them is the heteroleptic analogous of C1 (ARM13) and the other two have a thiophene (ARM7) and phenyl (ARM11) spacer between the pyridine and the $\mathrm{COOH}$ anchoring group, inserted with the aim of increasing the distance between the $\mathrm{TiO}_{2}$ surface and the iron centre and improving, at the same time, the light harvesting capabilities. By combining different experimental and computational techniques, here we report the synthesis of these new Fe-complexes, characterize their optical and redox properties, and investigate their photovoltaic performances when employed in DSSCs. Notably we obtained the best power conversion efficiency of $1.44 \%$ for the heteroleptic ARM13 complex that is the highest efficiency ever reported for an iron complex sensitized solar cell. Both the gain in efficiency derived from the use of $\mathrm{Mgl}_{2}$-based electrolytes, and the loss in efficiency introduced by the conjugated spacers in the dye structure were rationalized by employing DFT calculations of the isolated dye sensitizers and dye/ $\mathrm{TiO}_{2}$ interface models. The results presented here clearly provide important design rules to engineer the chemical structure of iron complexes for solar cell applications, where the use of aromatic bridges should be combined with electron donating and acceptor groups in order to avoid local $\pi-\pi^{*}$ excitations which are detrimental for obtaining an adequate charge separation.

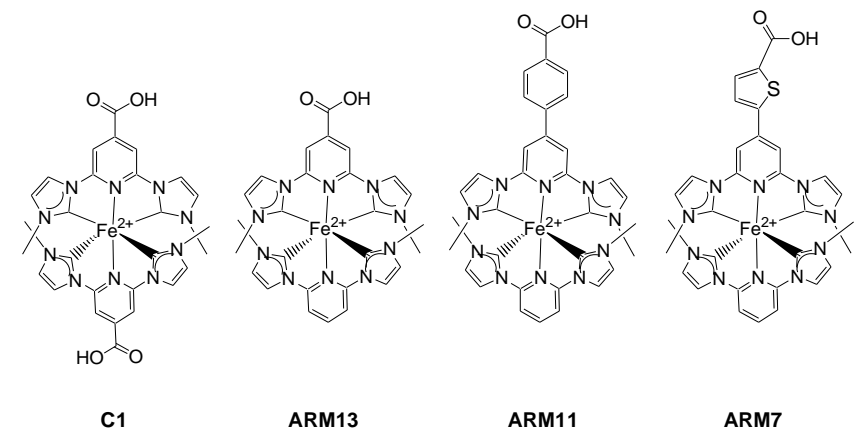

Figure.1 Chemical structures of Fe(II) NHC complexes studied in this work, the counterion is $\mathrm{PF}_{6}^{-}$in every case.

\section{Experimental}

\subsection{Materials and methods}

The starting materials and reagents were commercially available and used as received. ARM13 was prepared according to ref. $^{30}$ Solvents were purified by standard procedures and purged with argon before use. All other chemicals used in this work were of analytical grade and were used without further purification until or unless stated, and all reactions were performed under an inert atmosphere of argon. Chromatographic separations were carried out on silica gel (60-120 mesh). ${ }^{1} \mathrm{H}(400 \mathrm{MHz})$ and ${ }^{13} \mathrm{C}$ NMR $(100 \mathrm{MHz})$ spectra were taken on a DRX400 Bruker spectrometer at ambient temperature. High-resolution mass spectrometry (HRMS) data was obtained by using Bruker micrOTOF-Q spectrometer. UV-vis spectra were recorded in a $1 \mathrm{~cm}$ path length quartz cell on a LAMBDA 1050 (Perkin Elmer), spectrophotometer.

Electrochemical data for complexes in solution were obtained using a Radiometer PST006 potentiostat. A singlecompartment cell was used with an $\mathrm{Ag} / \mathrm{AgCl}$ as reference electrode, glassy carbon as working electrode and Pt wire as counter electrode, the supporting electrolyte was $0.1 \mathrm{M}$ $\mathrm{NBu}_{4} \mathrm{PF}_{6}$ in dry acetonitrile. Solutions containing ca. $2 \times 10^{-3} \mathrm{M}$ analyte were degassed by purging with nitrogen. All $E_{1 / 2}$ values were calculated from $\left(E_{\mathrm{pa}}+E_{\mathrm{pc}}\right) / 2$ at a scan rate of 100 $\mathrm{mV} \mathrm{s}{ }^{-1}$ and referenced to $\mathrm{Fc} / \mathrm{Fc}^{+}$. All potentials were quoted versus SCE.

\subsection{Synthesis}

Compound 3. To a solution of $\mathbf{2}$ (see SI for preparation) $(0.2 \mathrm{~g}$, $0.69 \mathrm{mmol})$ in toluene $(5 \mathrm{~mL})$ was added a solution of 5 carboxy-2-thiophene-boronic acid pinacolester $(0.175 \mathrm{~g}, 0.69$ $\mathrm{mmol}$ ) and $\mathrm{K}_{2} \mathrm{CO}_{3}(0.285 \mathrm{~g}, 2.07 \mathrm{mmol})$ in methanol $(5 \mathrm{~mL})$. The mixture was degassed with Argon for 30 min then $\mathrm{PdCl}_{2}$ (dppf) $(0.050 \mathrm{~g}, 0.069 \mathrm{mmol})$ was added and the solution was refluxed at $80{ }^{\circ} \mathrm{C}$ for $8 \mathrm{~h}$. After completion of reaction, the reaction mixture was filtered through celite powder and washed with $10 \% \mathrm{MeOH}$ in DCM. After evaporation of solvents, the residue was purified by column chromatography over silica gel using DCM/methanol/triethylamine (TEA) $(9 / 1 / 0.1)$ mixture as the eluent to give the product as grey 
solid (0.21 g, 90\% yield). ${ }^{1} \mathrm{H}$ NMR (400 $\mathrm{MHz}, \mathrm{CDCl}_{3}+\mathrm{TEA}, \delta$ ppm): $8.33(\mathrm{~s}, 2 \mathrm{H}), 7.61(\mathrm{~s}, 2 \mathrm{H}), 7.54-7.55(\mathrm{~m}, 1 \mathrm{H}), 7.48(\mathrm{~d}$, $\mathrm{J}=3.8 \mathrm{~Hz}, 1 \mathrm{H}), 7.36(\mathrm{~s}, 2 \mathrm{H}), 7.17(\mathrm{~s}, 2 \mathrm{H}) .{ }^{13} \mathrm{C} \mathrm{NMR}(101 \mathrm{MHz}$, DMSO-d6+TEA, $\delta$ ppm): 163.0, 149.15, 147.0, 145.2, 137.5, 136.6, 134.4, 130.7, 129.5, 117.7, 106.5. ESI-HRMS calcd for $\mathrm{C}_{16} \mathrm{H}_{12} \mathrm{~N}_{5} \mathrm{O}_{2} \mathrm{~S} \mathrm{~m} / \mathrm{z}=338.0706$. Found: 338.0686 .

Compound 4. To a solution of $2(0.18 \mathrm{~g}, 0.62 \mathrm{mmol})$ in toluene $(5 \mathrm{~mL})$ was added to a solution of 4-carboxy-benzene-boronic acid $(0.093 \mathrm{~g}, 0.56 \mathrm{mmol})$ and $\mathrm{K}_{2} \mathrm{CO}_{3}(0.258 \mathrm{~g}, 1.86 \mathrm{mmol})$ in methanol $(5 \mathrm{~mL})$. The mixture was degassed with Argon for 30 min, $\mathrm{PdCl}_{2}(\mathrm{dppf})(0.046 \mathrm{~g}, 0.062 \mathrm{mmol})$ was added and refluxed at $80{ }^{\circ} \mathrm{C}$ for $8 \mathrm{~h}$. After completion of reaction, the reaction mixture was filtered through celite powder and washed with $10 \% \mathrm{MeOH}$ in dichloromethane (DCM) $(50 \mathrm{~mL})$. After solvents evaporation, the residue was purified by column chromatography over silica gel using DCM/methanol/TEA $(9 / 1 / 0.1)$ mixture as the eluent to yield a grey solid $(0.19 \mathrm{~g}$, 92\% yield). ${ }^{1} \mathrm{H}$ NMR (400 MHz, DMSO-d6+TEA, $\delta \mathrm{ppm}$ ): 13.22 (bs, $1 \mathrm{H}), 8.88(\mathrm{~s}, 2 \mathrm{H}), 8.28(\mathrm{~s}, 2 \mathrm{H}), 8.21(\mathrm{~d}, J=8.47 \mathrm{~Hz}, 2 \mathrm{H}), 8.12-$ $8.14(\mathrm{~m}, 4 \mathrm{H}), 7.19(\mathrm{~s}, 2 \mathrm{H}) .{ }^{13} \mathrm{C} \mathrm{NMR}(100 \mathrm{MHz}$, DMSO$d_{6}+$ Pyridine $-d_{5}+$ TEA $\delta$ ppm): 167.46, 153.56, 148.94, 140.50, $132.72,130.67,130.36,128.31,117.56,108.25$. ESI-HRMS calcd for $\mathrm{C}_{18} \mathrm{H}_{14} \mathrm{~N}_{5} \mathrm{O}_{2} \mathrm{~m} / \mathrm{z}=332.1142$. Found: 332.1161 .

Ligand precursor L1. Compound 4 (0.18 g, $0.543 \mathrm{mmol})$ was charged in a $25 \mathrm{~mL}$ round bottomed flask and dissolved in $1 \mathrm{~mL}$ of DMF. Then added methyl iodide $(0.069 \mathrm{~mL}, 1.11 \mathrm{mmol})$ and heated the mixture at $130{ }^{\circ} \mathrm{C}$ for $1 \mathrm{~h}$. Desired compound was precipitated upon addition of diethyl ether. Solid was collected by filtration and washed thrice with diethyl ether and dried under vacuum. Then the solid was dissolved in minimum amount of DMSO (ca. $2 \mathrm{~mL}$ ) and added saturated $\mathrm{NH}_{4} \mathrm{PF}_{6}$ solution followed by $2 \mathrm{~N} \mathrm{HNO}_{3}$ until the solution becomes acidic $(\mathrm{pH} \approx 2)$. The mixture was stirred until the product precipitated. Ligand $\mathbf{L} \mathbf{1}$ was collected by vacuum filtration and washed 3 times with water and then diethyl ether $(0.25 \mathrm{~g}, 71 \%$ yield). ${ }^{1} \mathrm{H}$ NMR $\left(400 \mathrm{MHz}, \mathrm{CD}_{3} \mathrm{CN}, \delta \mathrm{ppm}\right): 9.52(\mathrm{~s}, 2 \mathrm{H}), 8.28-$ $8.30(\mathrm{~m}, 4 \mathrm{H}), 8.20(\mathrm{~s}, 2 \mathrm{H}), 8.07(\mathrm{~d}, J=9.2 \mathrm{~Hz}, 2 \mathrm{H}), 7.67(\mathrm{~s}, 2 \mathrm{H})$. ${ }^{13} \mathrm{C}$ NMR (101 MHz, DMSO-d6, $\left.\delta \mathrm{ppm}\right): 167.95,155.14,146.53$, $137.59,137.34,137.13,130.49,127.90,125.40,119.76$, 111.93, 37.08. ESI-HRMS calcd for $\mathrm{C}_{20} \mathrm{H}_{19} \mathrm{~N}_{5} \mathrm{O}_{2} \mathrm{~m} / \mathrm{z}=180.5764$. Found: $180.5804\left[\mathrm{M}-2 \mathrm{PF}_{6}\right]$.

L2. Compound $3(0.1 \mathrm{~g}, 0.296 \mathrm{mmol})$ was charged in a $25 \mathrm{~mL}$ round bottomed flask and dissolved in $1 \mathrm{~mL}$ of DMF. Methyl iodide $(0.038 \mathrm{~mL}, 0.607 \mathrm{mmol})$ was added, and the mixture was heated at $130{ }^{\circ} \mathrm{C}$ for $1 \mathrm{~h}$. The desired compound was precipitated upon addition of diethylether. The solid was collected by filtration and washed 3 times with diethylether and dried under vacuum. Then the solid was dissolved in minimum amount of DMSO (ca. $2 \mathrm{~mL}$ ) and a saturated $\mathrm{NH}_{4} \mathrm{PF}_{6}$ solution was added followed by $2 \mathrm{~N} \mathrm{HNO}_{3}$ until the solution becomes acidic $(\mathrm{pH} \approx 2)$. The mixture was stirred until precipitation and After vacuum filtration and washing 3 times with water and then diethyl ether, $\mathbf{L 2}$ was obtained as a pale brown solid ( $0.137 \mathrm{~g}, 70 \%$ yield). ${ }^{1} \mathrm{H}$ NMR ( $400 \mathrm{MHz}$, DMSO-d6, $\delta \mathrm{ppm}): 10.32(\mathrm{~s}, 2 \mathrm{H}), 8.78(\mathrm{~s}, 2 \mathrm{H}), 8.46(\mathrm{~s}, 2 \mathrm{H}), 8.12(\mathrm{~d}, J=3.8$ $\mathrm{Hz}, 1 \mathrm{H}), 8.01(\mathrm{~s}, 2 \mathrm{H}), 7.90(\mathrm{~d}, J=3.8 \mathrm{~Hz}, 2 \mathrm{H}), 3.98(\mathrm{~s}, 6 \mathrm{H}) .{ }^{13} \mathrm{C}$ NMR (101 MHz, DMSO-d6, $\delta$ ppm): 162.8, 148.15, 146.7,
$143.7,138.7,136.9,134.7,130.7,125.4,119.7,11.4,37.2$. ESIHRMS calcd for $\mathrm{C}_{18} \mathrm{H}_{17} \mathrm{~N}_{5} \mathrm{O}_{2} \mathrm{~S} \mathrm{~m} / \mathrm{z}=183.5546$, Found: 183.5642 $\left[\mathrm{M}-2 \mathrm{PF}_{6}\right]$

ARM7. To a solution of $\mathbf{L} 2(0.078 \mathrm{~g}, 0.118 \mathrm{mmol})$ and $\mathbf{L 3}^{22}$ (synthesized using literature procedure) $(0.063 \mathrm{~g}, 0.118 \mathrm{mmol})$ in $2 \mathrm{~mL}$ of anhydrous DMF was added $\mathrm{FeCl}_{2}(0.015 \mathrm{~g}, 0.118$ $\mathrm{mmol}$ ) and degassed the mixture with Argon for $10 \mathrm{~min}$. Then added $t$-BuOK $(0.053 \mathrm{~g}, 0.473 \mathrm{mmol})$ to the above mixture and stirred at room temperature for $20 \mathrm{~min}$. A saturated solution of $\mathrm{NH}_{4} \mathrm{PF}_{6}$ was added $(10 \mathrm{ml})$, followed by $2 \mathrm{~N} \mathrm{HNO}_{3}$ until the solution becomes acidic $(\mathrm{pH} \approx 2)$ and the precipitate was collected by filtration. Then the crude was further purified on silica gel column chromatography using acetone $/ \mathrm{H}_{2} \mathrm{O} / \mathrm{KNO}_{3}$ (sat) = 10: 3: 0.5 mixture. The reddish fraction was collected and after the evaporation of acetone, the left solution was treated with a saturated solution of $\mathrm{NH}_{4} \mathrm{PF}_{6}$ followed by $2 \mathrm{~N}$ $\mathrm{HNO}_{3}$ until the solution becomes acidic $(\mathrm{pH} \approx 2)$. Affording the precipitation of the complex, it was then filtered, washed with distilled water, and dried under vacuum. The isolated ARM-7 was obtained as a reddish colour $(0.012 \mathrm{~g}, 11 \%$ yield $) .{ }^{1} \mathrm{H} N M R$ (400 MHz, CD $\mathrm{CN}_{3} \delta \mathrm{ppm}$ ): $8.19(\mathrm{t}, J=8.2 \mathrm{~Hz}, 1 \mathrm{H}), 8.12$ (d, $J=$ $2.18 \mathrm{~Hz}, 2 \mathrm{H}), 8.05(\mathrm{~s}, 2 \mathrm{H}), 8.00(\mathrm{~d}, J=2.18 \mathrm{~Hz}, 2 \mathrm{H}), 7.96(\mathrm{~d}, J=$ 3.99, 1H) 7.90 (d, J= 3.99, 1H), $7.74(\mathrm{~d}, J=8.18,2 \mathrm{H}), 7.01$ (d, $J=$ 2.19, $2 \mathrm{H}), 7.00(\mathrm{~d}, J=2.19,2 \mathrm{H}), 2.57(\mathrm{~s}, 6 \mathrm{H}), 2.51(\mathrm{~s}, 6 \mathrm{H}) .{ }^{13} \mathrm{C}$ NMR $\left(100 \mathrm{MHz}, \mathrm{CD}_{3} \mathrm{CN}, \delta \mathrm{ppm}\right): 200.67,200.56,162.69$, $154.87,154.45,146.61,142.73,139.20,135.13,128.70$, $127.19,127.12,117.08,116.97,105.97,102.35,35.27,35.03$. ESI-HRMS calcd for $\mathrm{C}_{31} \mathrm{H}_{28} \mathrm{FeN}_{10} \mathrm{O}_{2} \mathrm{~S} \mathrm{~m} / \mathrm{z}=330.0728$, Found: $330.0814\left(\mathrm{M}-2 \mathrm{PF}_{6}\right)$.

ARM11. To a solution of Ligand L1 $(0.092 \mathrm{~g}, 0.142 \mathrm{mmol})$ and $\mathbf{L 3}^{22}$ (synthesized using literature procedure) $(0.075 \mathrm{~g}, 0.142$ $\mathrm{mmol})$ in $2 \mathrm{~mL}$ of anhydrous DMF was added $\mathrm{FeCl}_{2}(0.018 \mathrm{~g}$, $0.142 \mathrm{mmol}$ ) and degassed the mixture with Argon for $10 \mathrm{~min}$. Then added $t$-BuOK $(0.064 \mathrm{~g}, 0.568 \mathrm{mmol})$ to the above mixture and stirred at room temperature for $20 \mathrm{~min}$. A saturated solution of $\mathrm{NH}_{4} \mathrm{PF}_{6}$ was added $(10 \mathrm{ml})$ followed by $2 \mathrm{~N} \mathrm{HNO}_{3}$ until the solution becomes acidic $(\mathrm{pH} \approx 2)$ and the precipitate was collected by filtration. Then the crude was further purified on silica gel column chromatography using acetone $/ \mathrm{H}_{2} \mathrm{O} / \mathrm{KNO}_{3}$ (sat) = 10: 3: 0.5 mixture. The orange fraction was collected and after the evaporation of acetone, the left solution was treated with a saturated solution of $\mathrm{NH}_{4} \mathrm{PF}_{6}$ followed by $2 \mathrm{~N} \mathrm{HNO}_{3}$ until the solution becomes acidic $(\mathrm{pH} \approx 2)$. Affording the precipitation of the complex, it was then filtered, washed with distilled water and dried under vacuum. The isolated ARM-11 was obtained as orange colour (0.016 g, $12 \%$ yield). ${ }^{1} \mathrm{H}$ NMR (400 MHz, $\mathrm{CD}_{3} \mathrm{CN}, \delta \mathrm{ppm}$ ): 8.27 (d, $J=8.32 \mathrm{~Hz}, 2 \mathrm{H}), 8.19(\mathrm{t}, J=8.12 \mathrm{~Hz}, 1 \mathrm{H}), 8.15(\mathrm{~d}, J=8.32 \mathrm{~Hz}$, $2 \mathrm{H}), 8.11(\mathrm{~d}, J=2.02 \mathrm{~Hz}, 2 \mathrm{H}), 8.10(\mathrm{~s}, 2 \mathrm{H}), 8.01(\mathrm{~d}, J=2.02 \mathrm{~Hz}$, $2 \mathrm{H}), 7.74(\mathrm{~d}, J=8.15,2 \mathrm{H}), 7.02(\mathrm{~d}, J=2.00 \mathrm{~Hz}, 2 \mathrm{H}), 7.00$ (d, $J=$ $2.02 \mathrm{~Hz}, 2 \mathrm{H}), 2.56(\mathrm{~s}, 6 \mathrm{H}), 2.52(\mathrm{~s}, 6 \mathrm{H})$. ESI-HRMS calcd for $\mathrm{C}_{33} \mathrm{H}_{30} \mathrm{FeN}_{10} \mathrm{O}_{2} \mathrm{~m} / \mathrm{z}=327.0946$, Found: 327.1075 (M-2PF 6 ).

\subsection{Cell fabrication}

The FTO slides for electrode fabrication were cleaned by sequential ultra-sonication in Alconox ${ }^{\circledR} /$ water and 2-propanol 
for $10 \mathrm{~min}$ each. After drying at room temperature (RT) the resulting slides were heated at $450{ }^{\circ} \mathrm{C}$ for $20 \mathrm{~min}$ to remove residual organic contaminants. The blocking underlayer was fabricated by spin coating (10 s at $1000 \mathrm{rpm}$ followed by $20 \mathrm{~s}$ at $2000 \mathrm{rpm}$ ) a $0.3 \mathrm{M}$ titanium tetraisopropoxide solution in 1butanol followed by heating at $500{ }^{\circ} \mathrm{C}$ for $15 \mathrm{~min}$. Ca. $16 \mu \mathrm{m}$ thick transparent $\mathrm{TiO}_{2}$ were obtained by repeating twice the blade casting of 18NR-T paste according to the classical scotch tape methods. Each casting was followed by a sintering process in an oven according to the following temperature program: $25-120^{\circ} \mathrm{C}(10 \mathrm{~min}), 120-450{ }^{\circ} \mathrm{C}(30 \mathrm{~min}), 450{ }^{\circ} \mathrm{C}(20$ $\mathrm{min}), 450-500{ }^{\circ} \mathrm{C}(10 \mathrm{~min}), 500{ }^{\circ} \mathrm{C}(10 \mathrm{~min})$. Cooling at RT was accomplished by removing the electrodes from the oven and storing them at $\mathrm{RT}$ in a dessicator. $\mathrm{TiCl}_{4}$ treatment was performed by drop casting a $0.4 \mathrm{M}$ aqueous $\mathrm{TiCl}_{4}$ solution on top of the $\mathrm{TiO} 2$ film followed by overnight hydrolysis at room temperature in a closed case. Later, after removing the excess $\mathrm{TiCl}_{4}$ solution by rinsing with deionized water, a final annealing stage was carried out at $450{ }^{\circ} \mathrm{C}$ for $30 \mathrm{~min}$. After having optimized of the dye adsorption process, the following conditions were deemed the best for optimal light harvesting: C1 and ARM13 were chemisorbed on $\mathrm{TiO}_{2}$ film by using 0.2 $\mathrm{mM}$ dye/ $0.04 \mathrm{mM}$ chenodeoxycholic acid (CDCA) acetonitrile baths; ARM7 and of ARM11 were chemisorbed from a more concentrated $0.5 \mathrm{mM}$ acetonitrile solution in the absence of CDCA. N 719 was adsorbed from $0.2 \mathrm{mM}$ ethanolic baths.

$0.25 \mathrm{~cm}^{2}$ electrocatalytic PEDOT films for use as counter electrodes were fabricated by potentiodynamic electropolymerization on the FTO surface delimited by square surlyn 25 masks. The electropolymerization occurred between the working (FTO) and counter electrode (Ti sheet, $4 \mathrm{~cm}^{2}$ ) facing each other at a distance of ca. $3 \mathrm{~mm}$ by exploiting 2 potential sweeps in cyclic voltammetry mode (0-1.6 V vs SCE at $50 \mathrm{mV} / \mathrm{s}$ ) in an electrolyte made of $10^{-2} \mathrm{M}$ EDOT in a $0.1 \mathrm{M} \mathrm{LiClO}_{4}$ in acetonitrile. Cells were prepared in an open configuration using surlyn 25 as a spacer. Redox electrolytes were prepared according to the following formulations: electrolyte 2 (el2): 0.1 $\mathrm{M} \mathrm{LI}, 0.6 \mathrm{M} \mathrm{PMII}, 0.1 \mathrm{M} \mathrm{I}_{2}, 0.1 \mathrm{M} \mathrm{MgI}_{2}, 0.1 \mathrm{M}$ GuNCS in Acetonitrile (ACN). A further formulation conceived for enhancing photocurrent was named electrolyte 3 (el3) and consisted of $0.1 \mathrm{M} \mathrm{LI}, 0.6 \mathrm{M}$ PMII, $0.1 \mathrm{M} \mathrm{I}_{2}, 0.1 \mathrm{M} \mathrm{MgI}_{2}, 0.1 \mathrm{M}$ GuNCS, $0.1 \mathrm{M}$ TBAI in acetonitrile.

\subsection{Characterization of dye-sensitized electrodes and DSSCS}

Cyclic voltammetry (CVs) of the Fe(II)NHC-sensitized films used as working electrodes were carried out at a scan rate of 50 $\mathrm{mV} / \mathrm{s}$ with a PGSTAT $302 \mathrm{~N}$ potentiostat in acetonitrile/0.1 M $\mathrm{LiClO}_{4}$ solution, using a three electrode cell with a platinum wire as counter electrode and double jacketed SCE as a reference. SEM imaging of the anatase mesoporous films were carried out at the Department of Physics of the University of Trento with a JEOL JSM-7001F FEG-SEM. Surface morphology images were acquired in top-down and tilted mode whereas cross section analysis was performed putting the films on a $90^{\circ}$ stub. Absorption spectra of the $\mathrm{Fe}(\mathrm{II}) \mathrm{NHC}$ sensitized electrodes were obtained in transmission mode with an Agilent Cary 300 UV-Vis spectrophotometer. The spectra were collected against the background constituted by an otherwise identical $\mathrm{TiO}_{2}$ film supported on FTO.

Nanosecond laser experiments on $\mathrm{Fe}(\mathrm{II}) \mathrm{NHC}$ sensitized $\mathrm{TiO}_{2}$ films were recorded with a previously described spectrometric apparatus. ${ }^{36}$ In $\mu \mathrm{s}$-s region, the laser energy was adjusted to $500 \mu \mathrm{J} / \mathrm{cm}^{2} /$ pulse by acting on the Q switch and laser power supply and by interposing various optical elements to defocus and attenuate the beam in order to achieve a homogeneous excitation of whole sensitized surface on the optical path of the monochromatic probe beam. Various oscilloscope input impedances were used to amplify the $\mathrm{S} / \mathrm{N}$ of trace (from 50 Ohm to $1 \mathrm{MOhm}$ ) in a given temporal window and each oscillographic trace was averaged over ca. 100 laser shots at a repetition rate of $1 \mathrm{~Hz}$. Experiments carried out at the maximum time resolution of our spectrometer (FWHM ca. 7 ns) were conducted with a $10 \mathrm{~mJ} / \mathrm{cm}^{2} /$ pulse, to get a better $\mathrm{S} / \mathrm{N}$ ratio without pre-amplification. Sensitized $\mathrm{TiO}_{2}$ films supported on FTO were held at $45^{\circ}$ degrees with respect to both the excitation and probe beam, to reflect the scattered laser away from the detector. The electrolyte could fill by capillarity the gap between the mesoporous film and a microscope slide pressed against it.

Photo-electrochemical experiments were performed with a PGSTAT 302N potentiostat equipped with an Abet sun simulator (AM 1.5G filter) setting the lamp irradiance at 0.1 $\mathrm{W} / \mathrm{cm}^{2}$. The JV curves were collected in cyclic voltammetry mode by linear sweeping applied potential at $20 \mathrm{mV} / \mathrm{s}$ from 0 $V$ to slightly larger potentials than the measured Voc of each cell. IPCE spectra were carried out with a custom made apparatus composed by a Xe lamp (Ceralux CL300BF) source focused into the entrance slit of a motorized Newport Cornerstone monochromator coupled to an optical fibre to provide monochromatic illumination of the sandwich solar cell. Incident irradiance, recorded with a calibrated silicon photodiode, and the photocurrent output of the cell, collected under short circuit conditions, were acquired via a National Instruments PXI 1033 system. To avoid collecting an excess of scattered light into the solar cell photoactive layer, cells were framed with a black tape mask having active area of $0.25 \mathrm{~cm}^{2}$. APCE spectra were obtained according to APCE = IPCE/LHE where LHE $(\lambda)=1-10^{-A(\lambda)}$ was computed using the absorbance $\left(A(\lambda)\right.$ ) of each sensitized $\mathrm{TiO}_{2}$ film in contact with the blank electrolyte. Electrochemical Impedance Spectroscopy (EIS) measurements were obtained with a PGSTAT 302N potentiostat applying to solar cells under dark condition a 10$\mathrm{mV}$ perturbation in the $10^{5}-10^{-1} \mathrm{~Hz}$ range and probing the forward potential region from the onset of the dark current onwards.

\subsection{Computational details}

Isolated dye molecules. Theoretical calculations were performed at the Density Functional Theory (DFT) level, within the modified B3LYP* functional (with a $15 \%$ of Hartree-Fock exchangecorrelation fraction) and $6-311 \mathrm{G}(\mathrm{d})$ basis set. We chose this functional since it has been tuned to properly describe the optical 
properties Fe(II) complexes, ${ }^{37}$ and its success is largely documented in the literature. ${ }^{38-40}$ The implicit effect of the methanol solvent environment was considered by employing the Polarizable Continuum Model (PCM). ${ }^{41}$ In all cases, we have considered the dye complexes in their low spin (singlet) state in view of their larger stability with respect to the high spin (triplet) configurations. For instance, the low spin ground state (GS) energy of C1 was found $1.76 \mathrm{eV}$ more stable compared to the same energy in its high spin state. The ground state oxidation potential (GSOP) has been estimated here as minus the Kohn-Sham (KS) energy of the highest occupied molecular orbital (HOMO) in solution. The approximate way to obtain an experimental estimate of the excited state oxidation potential (ESOP) is to subtract the adiabatic lowest excitation energy $\left(E_{0-0}\right)$ from the GSOP. Here we compare these experimental estimates with our calculated ESOPs obtained as ESOP $=$ GSOP $-E_{\max }$, where $E_{\max }$ is the maximum of the calculated absorption band. This approximation will provide slightly overestimated ESOPs, but we expect that the trend within the series of Fe complexes will be reliably reproduced. The ground state (GS) geometries of the considered dyes were fully optimized, and, in the Frank-Condon approximation, the vertical excitation energies were calculated by means of Time-Dependent DFT (TD-DFT). The simulated absorption spectra were built by convoluting the 50 lowest energy vertical transitions with Gaussian function of halfwidth at full-length of $0.17 \mathrm{eV}$. The character of the MLCT transitions has been analysed on the basis of the transition density matrices performed by using TheoDORE package. ${ }^{42}$ All set of calculations for the isolated dyes were carried out within the Gaussian09 suite of programs. ${ }^{43}$

$\mathrm{TiO}_{2} @$ Dye cluster models. The optimized GS structure of the C1 and ARM-13 dyes were adsorbed in a bidentate fashion, after having transferred the carboxylic proton to one surface oxygen, to a $\left(\mathrm{TiO}_{2}\right)_{82}$ cluster having dimensions about $2 \times 2 \mathrm{~nm}$. This cluster model was obtained by exposing the anatase bulk phase to the (101) surface and it has been successfully employed to reproduce the dye@ $\mathrm{TiO}_{2}$ opto-electronic properties in previous works. ${ }^{44,45}$ Despite the fact that this model was initially tested to reproduce the correct $\mathrm{TiO}_{2}$ band edge and relative dye-semiconductor energy levels ${ }^{46}$ by employing the standard B3LYP functional, the calculated interfacial energetics is very similar for both B3LYP and B3LYP* functionals (see the calculation for $\mathbf{C 1}$ in Figure S17). We will thus safely rely on the B3LYP* results for our discussion. The optimized $\mathrm{C1}_{0} @ \mathrm{TiO}_{2}$ and ARM13@TiO ${ }_{2}$ geometries were obtained by performing DFT calculations with the Perdew-Burke-Ernzerhof (PBE) functional, COnductor-like Screening MOde (COSMO) solvation model, ${ }^{47}$ and D2 Grimme's dispersion correction ${ }^{48}$ for treating the Van der Waals interactions; as they have been implemented in the Amsterdam Density Functional (ADF) package. ${ }^{49}$ In addition, Double/Triple Zeta Polarized (DZP/TZP) basis sets were used for $\mathrm{C}, \mathrm{N}, \mathrm{H}, \mathrm{S}, \mathrm{O}, \mathrm{Mg} / \mathrm{Fe}, \mathrm{Ti}$ atoms, respectively. To rationalize the effect of the $\mathrm{MgI}_{2}$ electrolyte on the dye $/ \mathrm{TiO}_{2}$ interface properties, we studied the $\mathrm{C} 1 @ \mathrm{Mg}-\mathrm{TiO}_{2}$ and ARM13@Mg- $\mathrm{TiO}_{2}$ systems by placing the $\mathrm{Mg}^{2+}$ cation between two $\mathrm{O}$ atoms of the $\mathrm{TiO}_{2}$ surface close to the dye and following the procedure detailed above for the geometry optimization. For the sake of consistency with the isolated dye calculations, the electronic structure of the dye@TiO ${ }_{2}$ system was calculated using the same level of theory (functional, basis set and solvent environment description) as the one described in the previous section. Even though the photovoltaic properties were measured in acetonitrile solvent, methanol solvent was used as continuum medium for both relaxation and electronic structure calculations. In spite of this, in a continuum-medium description, the results will be almost identical for both solvent environments in view of their similar dielectric constants ( $\varepsilon=32.613$ for methanol and $\varepsilon=35.688$ for acetonitrile).

The interface charge injection properties were estimated by following the diabatic-like scheme developed by Thoss and coworkers. $^{50}$ Within this method, the diabatic couplings are calculated by resorting to a Fermi golden rule framework, where the charge injection rates $k_{i n j}$ are calculated as follows: $\boldsymbol{k}_{\boldsymbol{i n j}}=$ $\frac{2 \pi}{\hbar} \sum_{k}\left|\boldsymbol{V}_{d \boldsymbol{k}}\right|^{2} \boldsymbol{\rho}\left(\boldsymbol{\varepsilon}_{\boldsymbol{k}}\right)$

Here $k_{\text {inj }}$ represents the sum over the manifold of $k \mathrm{TiO}_{2}$ acceptor states of interest, whereas $d$ is the dye donor state, $\left|V_{d k}\right|^{2}$ is the square of the coupling elements, $\rho\left(\varepsilon_{\mathrm{k}}\right)$ is the semiconductor partial density of states (DOS), and their product $\left|V_{d k}\right|^{2} \rho\left(\varepsilon_{k}\right)$ defines the so-called probability distribution $\Gamma\left(\varepsilon_{k}\right)$. The diabatic states for donor (dye) and acceptor $\left(\mathrm{TiO}_{2}\right)$ moieties were extracted by the localization of the MOs of the entire complex into the donor and acceptor species, thus ending up in a Fock matrix where the diagonal elements display the energies of the localized states, while the off-diagonal blocks include the coupling elements $V_{k d}$. In a final step, the corresponding hole/electron injection rates were calculating by applying the formula: $\tau(\mathrm{fs})=\frac{\mathbf{6 5 8}}{\Gamma(\mathrm{meV})}$

It is important to highlight that although all previous works involving dye@ $\mathrm{TiO}_{2}$ diabatic analysis were done with B3LYP functional, ${ }^{44,45}$ our results obtained with B3LYP* are comparable to those obtained with the B3LYP (see Figures S18 and S19 and Table S1).

\section{Results and Discussion}

\subsection{Synthesis}

The synthetic routes followed to prepare the complexes are presented in Scheme 1. The ligands precursors $\mathbf{L} \mathbf{1}$ and $\mathbf{L} \mathbf{2}$ were obtained in good yields via a Suzuki cross-coupling between the bromo pyridine $\mathbf{2}$ and the appropriate arylboronic acids. The target complexes where finally obtained by reaction of the appropriate ligands ( $\mathbf{L 1}, \mathbf{L} \mathbf{2}, \mathbf{L 3}^{22}$ and $\mathbf{L} \mathbf{4}^{26}$ ) with $\mathrm{FeCl}_{2}$ in the presence of $t$-BuOK as the base. 
<smiles></smiles>

$\mathrm{RB}(\mathrm{OR})_{2}$

$\operatorname{Pd}(\mathrm{dppf}) \mathrm{Cl}_{2}(10 \%)$

$\underset{\mathrm{K} 2 \mathrm{CO}_{3}}{\text { Toluene/MeOH 1:1 }}$ $80^{\circ} \mathrm{C}, 8 \mathrm{~h}$



3, $\mathrm{R}=\mathrm{ThCOOH}, 90 \%$
4, $\mathrm{R}=\mathrm{PhCOOH}, 92 \%$

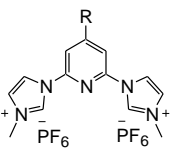
L1, R $=$ PhCOOH, $71 \%$
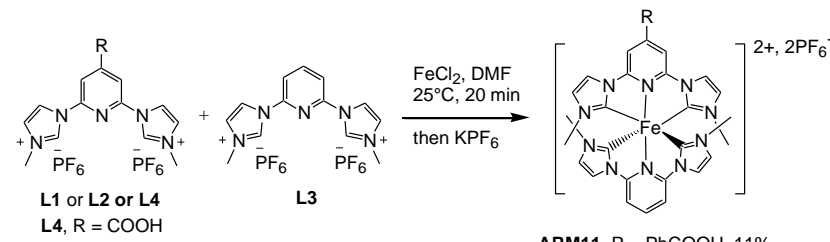

ARM11, $\mathrm{R}=\mathrm{PhCOOH}, 11 \%$ ARM7, $\mathrm{R}=\mathrm{ThCOOH}, 12 \%$ ARM13, $\mathrm{R}=\mathrm{COOH}, 15 \%$

Scheme 1. Synthesis of ligand precursors and complexes

\subsection{Electronic and Electrochemical properties}

The UV-Vis spectra recorded in methanol solution are shown in Figure 2 and the corresponding data gathered in Table 1.

All the complexes displayed three distinct absorption bands. The band at higher energy (250-330 nm) is assigned to $\pi-\pi^{*}$ transition, while the two other bands, in the lower energy region, correspond to the Fe-carbene MLCT transitions (340$420 \mathrm{~nm}$ ) and Fe-Pyridine MLCT transitions (420-600 nm). Passing from the homoleptic $\mathbf{C 1}$ complex to the heteroleptic ARM13, the lowest-energy MLCT band is blue-shifted $(0.16 \mathrm{eV})$ and less intense (from 18582 to $12375 \mathrm{M}^{-1} \mathrm{~cm}^{-1}$ ), whereas, as expected, ARM7 (thiophene linker) and ARM11 (phenyl linker) show an increased higher molar extinction coefficients with respect to ARM13 thanks to extended $\pi$-conjugation. In particular, the thiophene tethered complex presents the

higher and red-shifted absorption band $\left(\lambda_{\max }=499 \mathrm{~nm}, \varepsilon=\right.$ $16719 \mathrm{M}^{-1} \mathrm{~cm}^{-1}$ ) with respect to the phenyl tethered analogous $\left(\lambda_{\max }=479 \mathrm{~nm}, \varepsilon=15306 \mathrm{M}^{-1} \mathrm{~cm}^{-1}\right.$ for ARM11).

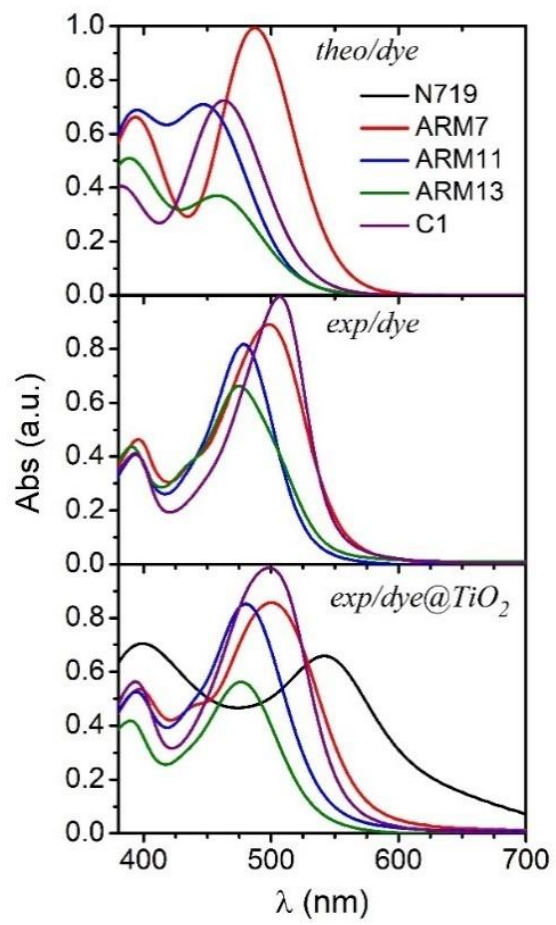

Figure 2. Calculated (top panel), recorded in methanol (middle panel) and recorded for the sensitized $\mathrm{Ti}_{2}$ bottom panel) MLCT absorption bands for $\mathrm{C}$ (purple), ARM13 (green), ARM7 (red) and ARM11 (blue). For the sake of comparison, the absorption spectrum of $\mathrm{N} 719$-sensitized $\mathrm{TiO}_{2}$ (black) is also
displayed. 
Table 1. Optical properties of C1, ARM7, ARM11 and ARM13 dyes: absorption maximum in $\mathrm{MeOH}$, absorption edge energies $\left(\mathrm{E}_{0-0,0}\right)$, absorption maxima on $\mathrm{TiO}_{2}$ $\left(E_{\max }\left(\mathrm{TiO}_{2}\right)\right.$ ) (soaked in Dye + CDCA solution where ARM7 and ARM11 values are simila with and without added $(D C A)$, calculated $E_{\max }$ with relative oscillator strengths and nature of the main single particle transitions contributing to these excited states (percentage for each transition). The absorption values are given in $\mathrm{nm}$.

\begin{tabular}{cccc|cc}
\hline \multicolumn{3}{c}{ Experiments } & \multicolumn{2}{c}{ Theory } \\
\hline Dye & $\begin{array}{c}\lambda_{\max } \\
\left(\varepsilon\left(\mathrm{M}^{-1} . \mathrm{cm}^{-1}\right)\right)\end{array}$ & $\mathrm{E}_{0-0}$ & $\begin{array}{c}\lambda_{\max } \\
\left(\mathrm{TiO}_{2}\right)\end{array}$ & $\begin{array}{c}\mathrm{E}_{\max } \\
\text { (Oscillator } \\
\text { strength) }\end{array}$ & $\begin{array}{l}\text { Transition } \\
(\%)\end{array}$ \\
& & & & 463 & $\mathrm{H}-2 \rightarrow \mathrm{L}+1$ \\
& 507 & 551 & 496 & $\begin{array}{c}40.309) \\
(45.4 \%)\end{array}$ & \\
& $(18582)$ & & & & $\mathrm{H}-1 \rightarrow \mathrm{L}$ \\
ARM13 & 475 & 528 & 478 & 461 & $\mathrm{H}-2 \rightarrow \mathrm{L}$ \\
& $(12375)$ & & & $(0.148)$ & $(63.4 \%)$ \\
ARM11 & 478 & 541 & 481 & 454 & $\mathrm{H}-1 \rightarrow \mathrm{L}$ \\
& $(15306)$ & & & $(0.271)$ & $(64.4 \%)$ \\
ARM7 & 499 & 551 & 502 & 487 & $\mathrm{H}-1 \rightarrow \mathrm{L}$ \\
& $(16725)$ & & & $(0.371)$ & $(67.1 \%)$ \\
\hline
\end{tabular}

TD-DFT calculations were carried out to precisely characterize the nature and topology of the MLCT absorption bands (Table 1), responsible of electron injection into the $\mathrm{TiO}_{2}$ when employed in DSCCs. The computed spectra for the four systems are plotted in the top panel of Figure 2. As reported in previous works for NHC-Fe(II) systems, ${ }^{26,28,32,51,52}$ the calculated spectra are slightly blue-shifted (up to $0.24 \mathrm{eV}$ in the case of C1) with respect to the experimental ones, but the trend within the series is accurately reproduced. The overall differences in the absorption features between the studied dyes are, indeed, captured: the increase in the absorption intensities in ARM11 and ARM7 with respect to ARM13 due to increase in conjugation; and the red-shift of $\mathbf{C 1}$ compared to its heteroleptic homologue, ARM13. The composition the main excitation of the MLCT bands is reported in Table 1, while the associated natural transition orbitals are shown in Figure S20 in Supporting Information. Interestingly, the lowest energy transitions $(\mathrm{H} \rightarrow \mathrm{L}$ ) are dark for all dyes (see Table S2), and the main MLCT transitions, composing the lowest-energy band, involve HOMO-1 and HOMO-2 and LUMO levels (note that for C1 LUMO and L+1 levels are degenerated due to the presence of two carboxylic groups).

The oxidation potentials of all the complexes were obtained from cyclic voltammetry measured in acetonitrile and the potential values against SCE are plotted in Figure 3, where also the conduction band edge of $\mathrm{TiO}_{2}$ and the redox potential of the $\mathrm{I}^{-} / \mathrm{I}_{3}^{-}$electrolyte is reported. As is apparent, the introduction of a thiophene (ARM7: $0.74 \mathrm{~V}$ vs SCE) or phenyl (ARM11: $0.70 \mathrm{~V}$ vs SCE) spacer reduces the oxidation potentials with respect to the ones measured for ARM13 and C1 ( 0.82 and $0.85 \mathrm{~V}$ vs SCE, respectively). This is most likely due to the extension of $\pi$-conjugation arising from thiophene and phenyl linkers. The GSOP of the dyes are, for all the systems, sufficiently more positive than the $\mathrm{I}^{-} / \mathrm{I}_{3}^{-}$redox potential, indicating that the electron transfer by the redox pair to regenerate the oxidized dye is thermodynamically favoured. The ESOPs, calculated as the difference between GSOPs and the adiabatic excitation energy $\left(E_{0-0}\right)$ estimated from the absorption edge, are, on the other hand, sufficiently more negative than the potential of $\mathrm{TiO}_{2}$ conduction band to have efficient electron injection.



Figure 3: Schematic energy levels vs SCE of C1, ARM13, ARM11 and ARM7 as and DFT/TDDFT calculations (red). The $\mathrm{TiO}_{2}$ conduction band minimum (CBM) and the potential of the $\mathrm{I}^{-} / \mathrm{I}_{3}^{-}$electrolyte are also plotted.

As is apparent in Table S3 in Supporting Information and Figure 3, the calculated redox levels are close, although slightly overestimated, to the experimental ones and, more importantly, provide the correct trend within the series of compounds, thus validating the employed level of theory for reproducing the electronic structure of the sensitizers in solution.

The thermodynamic properties relevant to cell operation, namely the ground and excited state oxidation potentials, were also assessed on the sensitized films, to include the perturbation to the dye electronic levels exerted by the interaction with the semiconductor surface. Cyclic voltammetry of the sensitized films immersed in $0.1 \mathrm{M}$ of $\mathrm{LiClO}_{4}$ in acetonitrile (Figure S27) reveals quasi-reversible $\mathrm{Fe}(\mathrm{II}) / \mathrm{Fe}(\mathrm{III})$ oxidation processes characterized by $\Delta E \approx 100 \mathrm{mV}$ for all the complexes, indicative of fast electron transfer kinetics. The $E_{1 / 2}$ potential found in the series of complexes under investigation shows only a mild variation in moving from ARM7 to ARM13, suggesting that the ligand environment stabilizes the highest occupied orbitals, which in these complexes have a prevailing metal $d_{\pi}$ contribution, in a similar fashion. ARM7, ARM11 and ARM13 exhibit $E_{1 / 2}$ of $560 \mathrm{mV}, 550 \mathrm{mV}$ and $600 \mathrm{mV}$, respectively. Compared to the data obtained for the same complexes in solution, we observe a systematic cathodic shift of the order of $100-150 \mathrm{mV}$, which may be explained by the decreased back bonding caused by the deprotonation of the carboxylic group upon binding of the complexes to the $\mathrm{TiO}_{2}$ surface. We also observe that the relative positioning of the $E_{1 / 2}$ potentials is, within the series of heteroleptic complexes, qualitatively consistent with the trend observed in solution where ARM13 exhibits the strongest anodic potential probably due to the stronger electron withdrawing effect caused by the carboxylic group directly attached to the NHC ligand. The cathodic shift of the ground state potentials makes the excited state of the dyes loaded on titania slightly better reductants than in solution. By using the onset of the absorption spectrum of the sensitized thin film we obtain $E^{*}$ ox 
equal to $-1.49 \mathrm{~V}$ for ARM7, $-1.62 \mathrm{~V}$ for ARM11 and $-1.57 \mathrm{~V}$ for ARM13, making injection into the $\mathrm{TiO}_{2}$ acceptor states of titania exergonic by at least $-0.9 \mathrm{eV}$, if we consider the positioning of the $\mathrm{TiO}_{2}$ flat band potential at ca. $-0.7 \mathrm{~V}$ vs SCE in organic solvents containing lithium cations. ${ }^{53}$

\subsection{Steady State and Transient Absorption Spectroscopy of sensitized thin films}

In order to optimize the light harvesting, at least at wavelengths resonant with the MLCT maximum of the $\mathrm{Fe}(\mathrm{II}) \mathrm{NHC}$ dyes, we have prepared relatively thick titania films, by repeated casting and annealing of a commercial terpineol based anatase paste (Greatcell Solar 18 NRT). The crosssectional analysis of these photoanodes (Figure S28) confirms their nanocrystalline nature, showing a homogeneous network of nanoparticles having an approximate size of ca. $20 \mathrm{~nm}$ (Figure S29) which extends for a thickness of about $17 \mu \mathrm{m}$. Underneath the porous network, which allows electrolyte permeation, one can observe the presence of the compact $\mathrm{TiO}_{2}$ blocking underlayer (BUL) which serves as a means of improving the adhesion of the porous layer to the ohmic contact and to insulate the electron collector from recombination reactions involving the electrolyte and the exposed surface of FTO.

The absorption spectra of sensitized $\mathrm{BUL}-\mathrm{TiO}_{2}$ electrodes, measured in transmittance mode against an identical undyed $\mathrm{TiO}_{2} /$ FTO are shown in Figure 2, together with the absorption spectrum of $\mathrm{N719}$ (black line) taken as a reference. All the $\mathrm{Fe}(\mathrm{NHC})$ complexes show an intense MLCT band between 480 and $500 \mathrm{~nm}$, followed by a weaker band at ca. $400 \mathrm{~nm}$. The light harvesting efficiency is larger than $90 \%$ for all the $\mathrm{Fe}(\mathrm{NHC})$ complexes under investigation, with the best efficiency found for ARM7 and C1, which couple maximum absorbance $\geq 2$ to spectral extension, which, in the case of ARM7, bearing a conjugated thiophene linker, extends to $650 \mathrm{~nm}$ in agreement with computational and spectroscopic results in fluid solution. Despite the improvement in light harvesting of the new designs, N719 still displays the best red responsivity, with two MLCT bands covering most of the visible spectrum and extending beyond $700 \mathrm{~nm}$. From $A(\lambda)=1000 \Gamma \varepsilon(\lambda)$ where $A$ is the electrode absorbance measured in transmission mode and $\Gamma$ and $\varepsilon(\lambda)$ are the surface concentration $\left(\mathrm{mol} / \mathrm{cm}^{2}\right)$ and the extinction coefficient $\left(\mathrm{M}^{-1} \mathrm{~cm}^{-1}\right)$ it is possible to estimate the coverage of the dyes, which were found all very similar, on the order of $0.12 \pm 0.10 \mu \mathrm{mol} / \mathrm{cm}^{2}$, confirming that the lower absorbance of the ARM13 sensitized film is related to its lower extinction coefficient.

Transient absorption spectroscopy (TAS) in the ns-ms time scale was next used to gain information about recombination and regeneration kinetics in $\mathrm{Fe}(\mathrm{II})$ sensitized $\mathrm{TiO}_{2}$ electrodes. In Figure 4, the transient difference spectra of ARM7@ $\mathrm{TiO}_{2}$, ARM11@TiO ${ }_{2}$ and ARM13@TiO 2 in contact with $0.1 \mathrm{M} \mathrm{LiClO}_{4}$ in $\mathrm{ACN}$, generated upon $532 \mathrm{~nm}$ laser excitation, are reported.

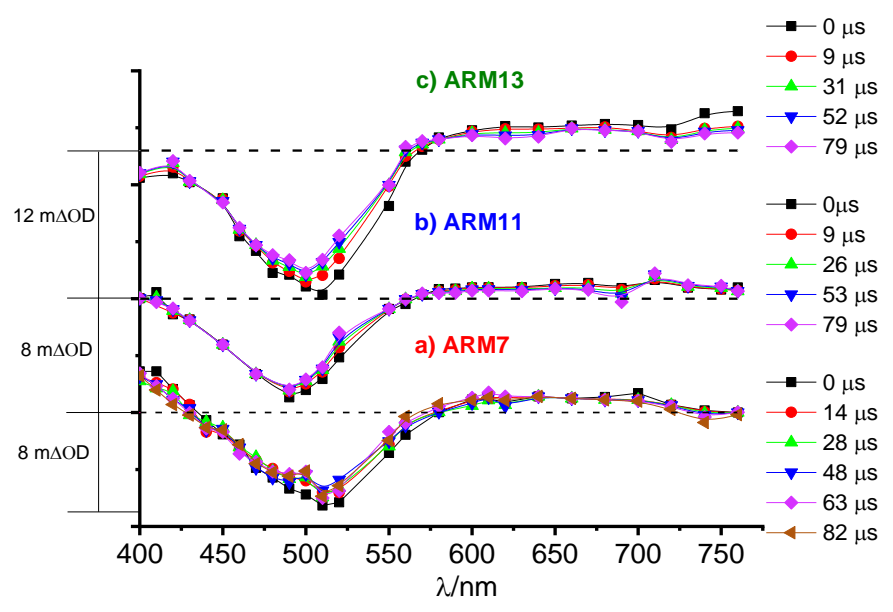

Figure 4. Transient absorption spectra recorded for ARM7 (a), ARM11 (b) and ARM13 (c) with $0.1 \mathrm{M} \mathrm{LiClO}_{4}$ in ACN. Input impedance is $350 \mathrm{Ohms}$

All spectra share common features, consistent with the formation, within the instrumental response function (300 ns with a $350 \Omega$ pre-amplifying impedance), of the charge separated state consisting in the formation of $\mathrm{Fe}(\mathrm{III}) / \mathrm{e}^{-}\left(\mathrm{TiO}_{2}\right)$ pairs. The main spectral signatures of the charge separated state are summarized by the intense bleaching of the MLCT ground state absorption centred at ca. $500 \mathrm{~nm}$, an isosbestic point at ca. $570 \mathrm{~nm}$, followed by a weaker flat absorption extending from ca. $600 \mathrm{~nm}$ to $750 \mathrm{~nm}$, assigned to mixed contribution from photoinjected electrons and LMCT transition to the photogenerated Fe(III). All these features appear to undergo basically no evolution in the $100 \mu \mathrm{s}$ time window selected and are consistent with previous results reported for the structurally related $\mathbf{C 1}$ dye. ${ }^{36}$ This indicates that injection occurs within the instrumental time response and that recombination occurs slowly, being largely incomplete after ca. $80 \mu \mathrm{s}$ after the excitation. The ground state bleaching of all dyes is red shifted (ca. 10-20 nm, depending on the dye) with respect to the ground state absorption recorded in Figure 2 relative to the dry $\mathrm{TiO}_{2}$ films in contact with air, and agrees with the respective ground state absorption bands observed when these films are in contact with the $\mathrm{Li}^{+}$and $\mathrm{Mg}^{2+}$ containing electrolytes (Figure S30), owing to a stark shift induced by surface adsorption of high charge density cations. $^{36,54}$

In the presence of inert electrolyte 3 (deprived from the iodine/iodide couple), the complete recovery of the charge separated states of all Fe(II) dyes, whose initial amplitude, observed at $500 \mathrm{~nm}$, is on the order of $7 \mathrm{~m} \triangle \mathrm{OD}$, occurs by electron recombination on a time window which extend up to $0.2 \mathrm{~s}$ under a laser pulse fluence of $500 \mu \mathrm{J} / \mathrm{cm}^{2} /$ pulse (Figure $5)$. 


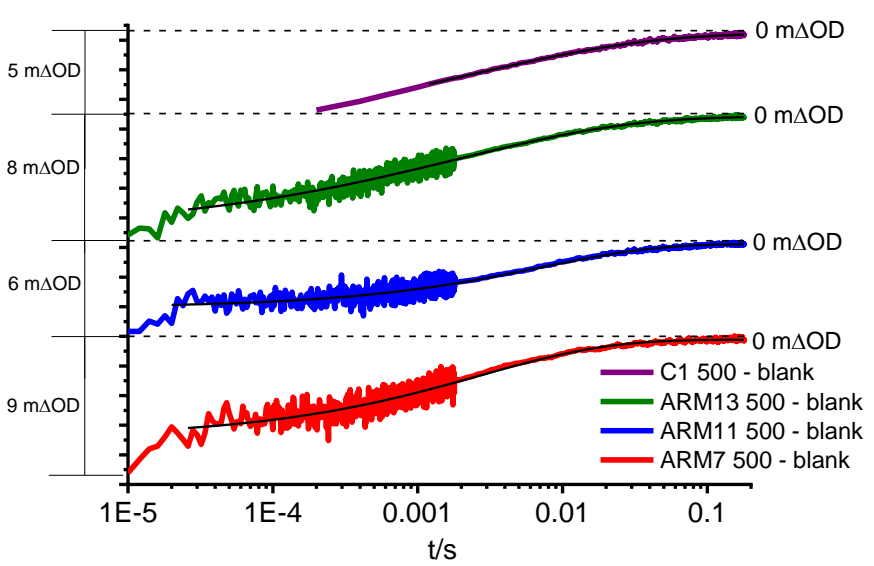

Figure 5: $500 \mathrm{~nm}$ recombination kinetics of the $\mathrm{Fe}(\mathrm{III}) / \mathrm{e}^{-}\left(\mathrm{TiO}_{2}\right)$ charge separated state probed at $500 \mathrm{~nm}$ with blank electrolyte 3 (deprived of lodine/iodide). The kinetics were constructed by joining traces recorded within different time windows, spanning the $10 \mu \mathrm{s}-2 \mathrm{~ms}$ interval (10 kOhm amplifier impedance) and 2-
$200 \mathrm{~ms}$ (1 Mohm amplifier). ARM7 (red line), ARM11 (blue line), ARM13 (green $200 \mathrm{~ms}$ (1 Mohm amplifier). ARM7 (red
line) and C1 (purple line) are compared.

These kinetics follow a stretched exponential function, according to eq. $1,{ }^{55}$ and span from ns to $\mathrm{ms}$, being originated by an energy distribution of semiconductor /electrolyte states from which recombination occurs according to an ample range of different rate constants.

$\mathrm{y}=\mathrm{a}+\mathrm{be} \mathrm{e}^{\left(-\frac{x}{\tau}\right)^{\mathrm{c}}}$

For all the species, the exponential parameters $\mathrm{c}$ is in the 0.34 0.54 range as reported in literature. The fitting revealed lifetimes of $2.7 \mathrm{~ms}, 7.1 \mathrm{~ms}, 2.0 \mathrm{~ms}$ and $2.3 \mathrm{~ms}$ for ARM7, ARM11, ARM13 and C1 respectively, thus $\mathrm{k}_{\text {rec }}$ sits in the $10^{-3}$ $10^{-2} \mathrm{~s}^{-1}$ range. The decay was also analysed by considering the $650 \mathrm{~nm}$ absorption, finding consistent results with the bleaching recovery, and confirming the identical origin of both bleach and long wavelength absorption (Figures S31).

When the iodide was present (Figure 6) (Electrolyte 3 without $\mathrm{I}_{2}$ ) a fast recovery of the bleach in the $10^{-6}-10^{-5} \mathrm{~s}$ interval was observed which is largely confined in the instrumental response function when the $10 \mathrm{kOhm}$ pre-amplifier was used, indicating that regeneration of the dye occurred with nearly quantitative efficiency.

The long lived stationary absorption that followed the bleach is indeed consistent with Stark effect, as a result of charging of the semiconductor films with electrons, which are no longer compensated by Fe(III) centres at the interface. As reported in our previous paper, ${ }^{36}$ all the transient spectra are indeed characterized by Stark features (Figures S32) which blue shift the ground state absorption of the dye and become dominant in the $\mathrm{ms}$ to $\mathrm{s}$ time scale and result in a broad absorption around $500 \mathrm{~nm}$, stronger in C1, weaker with the ARM13, ARM7 and ARM11.

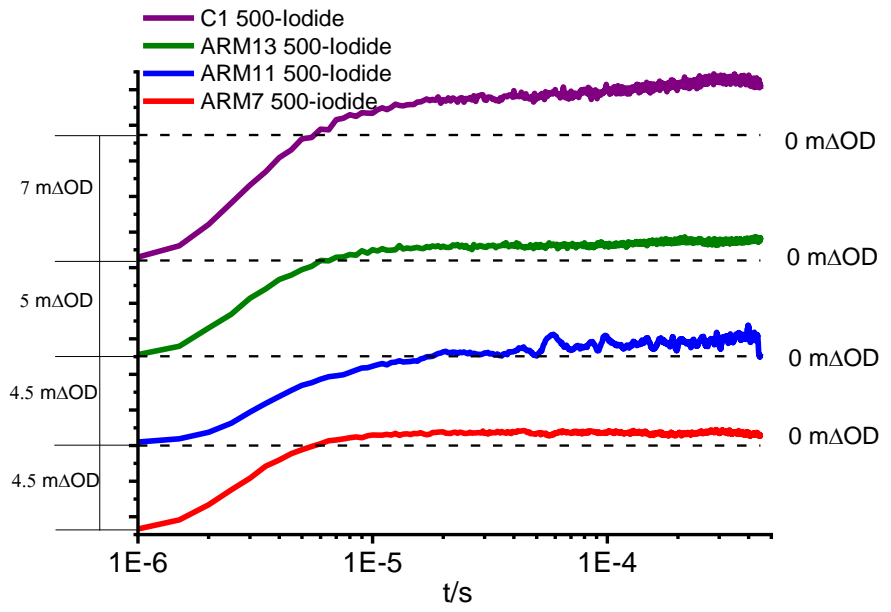

Figure 6: Positive absorption at $500 \mathrm{~nm}$ due to stark effect, as consequence of ARM13 (green line) and C1 (purple line). Electrolyte 3 (without $I_{2}$ )

The appearance of a Stark absorption after the bleach recovery confirm that most of the Fe(II) regeneration kinetics occur within a time scale of $3 \mu \mathrm{s}$, setting a lower limit of the regeneration time constant in the order $3.310^{5} \mathrm{~s}^{-1}$. This value, compared with a recombination rate which is from a hundred to a thousand of times slower would make the regeneration efficiency $\left(\eta_{\text {reg }}\right)$ of $\mathrm{Fe}(\mathrm{II})$ by the electrolyte practically quantitative. In order to evaluate the competition between recombination and regeneration at early time scales (ns-sub $\mu \mathrm{s}$ range) we have conducted measurements at the best time resolution of our spectrometer $(50 \Omega)$ which results in a instrumental Gaussian response function having FWHM of ca. $7 \mathrm{~ns}$ and a base of ca. 20 ns. Under these conditions the obtainment of traces with a good signal-to-noise ratio $(\mathrm{S} / \mathrm{N})$ requires higher energy density, which we set to 10 $\mathrm{mJ} / \mathrm{cm}^{2} /$ pulse. Since Fe(III) recovery by recombination is highly non mono-exponential and was less than $50 \%$ complete within the first $500 \mathrm{~ns}$, causing troubles with the fit reliability, we used as an empiric pseudo-first order time constant the time at half amplitude of the decay $\left(\tau_{1 / 2}\right)$ [56] and we decoupled recombination and regeneration time constants according to

$\mathrm{k}_{\mathrm{reg}}=\mathrm{k}_{\mathrm{app}}-\mathrm{k}_{\mathrm{rec}}$

where $k_{a p p}=1 / \tau_{1 / 2 a p p}$ and $k_{\text {rec }}=1 / \tau_{1 / 2 \text { rec }}$ are computed from the time constants observed in the presence of iodide couple (electrolyte 2 and 3 deprived of iodine) and with the inert electrolyte respectively (Figure S33(a) and (b) ). Under these conditions, we extracted a kinetic constant of the order of 1.5 $10^{7} \mathrm{~s}^{-1}$ which leads to a regeneration efficiency of $81 \%$. We thus conclude that, the ca. $200 \mathrm{mV}$ driving force displayed by the $\mathrm{Fe}(\mathrm{II}) /(\mathrm{III})$ couple in these complexes allows to achieve a nearly quantitative regeneration efficiency, which by combining the estimates at long and at short time scales we can judge on the order of $80-90 \%$. It is interesting to try to address the effect of high charge density cations in the electrolyte, since a large improvement in energy conversion 
performance was reported ${ }^{36}$ compared to earlier works. ${ }^{26}$ Although ns spectroscopy does not allow to resolve the charge injection dynamics, we found that injection occurs within the instrumental time response of our spectrometer at its best time resolution $\left(k_{i n j}>1.510^{8} \mathrm{~s}^{-1}\right)$ with an initial amplitude of the charge separated state $\left(\mathrm{Fe}(\mathrm{III}) / \mathrm{e}-\left(\mathrm{TiO}_{2}\right)\right.$ which was found doubled in the presence of $0.1 \mathrm{M} \mathrm{Li}^{+} / 0.1 \mathrm{M} \mathrm{Mg}^{2+}$ (Figure 534 ) consistent with a larger fraction of excited dye which undergoes injection on ultrafast time scales. This observation is consistent with the ca. $400 \mathrm{mV}$ positive shift in the $\mathrm{TiO}_{2}$ density of states revealed by cyclic voltammetry in an inert electrolyte composed of $0.6 \mathrm{M}$ PMIOTf/0.1 M TBAPF 6 /0.1M GuNCS (Figure S35). In the CV experiments we also observe a large increase in film conductivity which manifests in ca. 4-fold increase in the current associated to $\mathrm{TiO}_{2}$ electroactivity thanks to the charge compensating capabilities of $\mathrm{Li}^{+}$and $\mathrm{Mg}^{2+}$. These were reported to increase the ambipolar electron diffusion coefficient in mesoporous $\mathrm{TiO}_{2}$ films, favouring charge collection. ${ }^{57}$ However, such an effect, while beneficial in increasing cell performance, cannot influence the magnitude of the population of charge separated states observed at early time scales.

\subsection{Photovoltaic properties}

The performance of sensitized $\mathrm{TiO}_{2}$ electrodes using an $\mathrm{Mg}^{2+}$ containing electrolyte formulation, herein named el2 in ACN solution, that was previously successfully tested with the homoleptic C1 dye have been screened. ${ }^{36}$ Average CurrentVoltage curves under light and dark conditions, obtained on a set of 5 cells, equipped with PEDOT coated counter electrodes, are shown in Figure $7(\mathrm{a})$. The resulting efficiency parameters with their error are listed in Table 2.

Table 2: Photovoltaic parameters of ARM7, ARM11 and ARM13 compared with C1 and N719 with blocking under layer after double annealing PEDOT cells

\begin{tabular}{cccccc}
\hline Dyes & Electrolyte & $\begin{array}{c}\text { Jsc } \\
\left(\mathrm{mA} / \mathrm{cm}^{2}\right)\end{array}$ & $\begin{array}{c}\text { Voc } \\
(\mathrm{V})\end{array}$ & $\begin{array}{c}\mathrm{FF} \\
(\%)\end{array}$ & $\begin{array}{c}\text { PCE } \\
(\%)\end{array}$ \\
\hline N719 & $e / 2$ & 12.84 & 0.48 & 58 & $3.57 \pm 0.34$ \\
ARM7 & $e / 2$ & 3.55 & 0.44 & 60 & $0.94 \pm 0.11$ \\
ARM11 & $e / 2$ & 2.69 & 0.46 & 63 & $0.78 \pm 0.08$ \\
ARM13 & $e / 2$ & 3.95 & 0.49 & 61 & $1.18 \pm 0.10$ \\
C1 & $e / 2$ & 3.64 & 0.45 & 62 & $1.02 \pm 0.11$ \\
N719 & $e / 3$ & 12.87 & 0.50 & 57 & $3.68 \pm 0.52$ \\
ARM7 & $e / 3$ & 3.89 & 0.43 & 57 & $0.95 \pm 0.09$ \\
ARM11 & $e / 3$ & 2.90 & 0.45 & 62 & $0.81 \pm 0.10$ \\
ARM13 & $e / 3$ & 4.44 & 0.45 & 64 & $1.27 \pm 0.12$ \\
C1 & $e l 3$ & 4.38 & 0.43 & 59 & $1.11 \pm 0.17$ \\
\hline
\end{tabular}

First, we can observe that with e/2 in ACN, the performance of ARM13, C1 and ARM7 are quite aligned around photocurrent densities varying between $3.5 \mathrm{~mA} / \mathrm{cm}^{2}$ and $4 \mathrm{~mA} / \mathrm{cm}^{2}$, with a fairly good reproducibility $(<10 \%$ fluctuation) while the Vocs are around of $0.45 \mathrm{~V}$. With more detail, ARM7 achieved maximum PCE\% of $0.94 \%$ with Jsc $=3.55 \mathrm{~mA} / \mathrm{cm}^{2}, \mathrm{Voc}=440$ $\mathrm{mV}$ and $\mathrm{FF}=60$ whereas, $\mathrm{ARM} 11$ obtained $0.78 \%$ efficiency with $\mathrm{Jsc}=2.69 \mathrm{~mA} / \mathrm{cm}^{2}, \mathrm{Voc}=460 \mathrm{mV}$ and $\mathrm{FF}=63$. The best PCE\% of $1.2 \%$ was recorded for ARM13 which displayed the best combination of photocurrent, $3.95 \mathrm{~mA} / \mathrm{cm}^{2}$, photovoltage
(0.49 V) and FF (61\%). Notably ARM13 shows the lowest dark current which explains the best Voc among this series. The reference homoleptic complex C1 performs as expected, just slightly better than previously reported, probably due to the better harvesting associated to the use of thicker titania films, recording $1 \%$ efficiency. Despite its lower light harvesting ARM13 performs surprisingly well compared to $\mathbf{C 1}$ and, based on their similarity in regeneration efficiency and excited state energetics, we may hypothesize that ARM13 possesses a better electronic coupling for charge injection motivated by its asymmetric design. Under identical conditions N719 exhibited higher efficiency $3.57 \%$ due to its higher current density (12.8 $\mathrm{mA} / \mathrm{cm}^{2}$ ) associated to a Voc of ca. $0.5 \mathrm{~V}$. The larger voltage observed with $\mathbf{N 7 1 9}$ can be generally ascribed to its higher photocurrent, as placing neutral filters to reduce the irradiance and to set the Jsc to ca. $4 \mathrm{~mA} / \mathrm{cm}^{2}$, gave a Voc comparable to those recorded with the $\mathrm{Fe}(\mathrm{II})$ dyes.

The use of transparent Pt coated counter electrodes resulted, with the best performing dyes of the $\mathrm{Fe}(\mathrm{II}) \mathrm{NHC}$ series, in enhanced performance that we assigned to partial light reflection from the more reflective FTO/Pt electrodes with respect to the blue velvet like PEDOT films. For ARM13, the photocurrent density increased from $3.95 \mathrm{~mA} / \mathrm{cm}^{2}$ (PEDOT/FTO counter electrode) to $4.26 \mathrm{~mA}$ (Pt/FTO) and from $3.64 \mathrm{~mA} / \mathrm{cm}^{2}$ to $4.02 \mathrm{~mA} / \mathrm{cm}^{2}$ for $\mathbf{C 1}$, while Voc remained essentially unchanged. Overall PCE\% increase to $1.29 \%$ and 1.14\% for ARM13 and C1 respectively (Figure 7(b)).
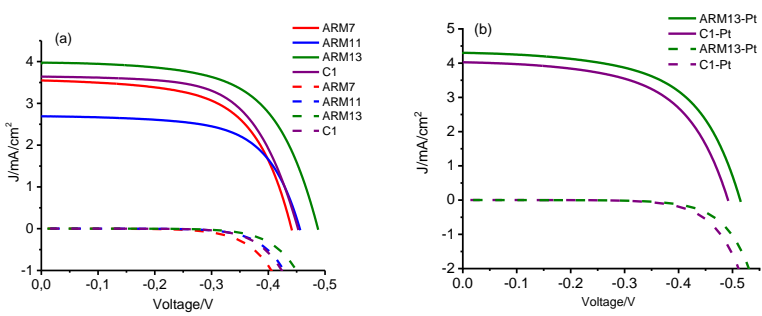

Figure 7: (a) J-V curves obtained with el2 under AM 1.5 illumination (solid lines) and in the dark (dashed lines). (b) C1 and ARM13 sensitized solar cell equipped illumination (solid lines) and in the dark (dashed lines)

With the Pt counter electrode, the use of a $\mathrm{TiO}_{2}$ scattering layer (Figure S36) further improved photocurrent, allowing to catch more efficiently light which is backscattered from the cathode, resulting in a $4.72 \mathrm{~mA} / \mathrm{cm}^{2}$ and $5.12 \mathrm{~mA} / \mathrm{cm}^{2} \mathrm{Jsc}$ for ARM13 and C1. This further modification of the $\mathrm{TiO}_{2}$ unfortunately translates in a reduction of the Voc, which leads to a PCE\% which is practically unchanged with respect to that of transparent cells without the scattering overlayer. However, with the same configuration, having optimized light management, $\mathbf{N} 719$ reached about $18 \mathrm{~mA} / \mathrm{cm}^{2}$, with a decreased $\mathrm{Voc}$ of $0.46 \mathrm{~V}$ (Figure S36) indicating that a strong dissipative process is acting within the $\mathrm{Fe}(\mathrm{II}) \mathrm{NHC}$ sensitized cells. Thus, we considered the reasons behind the lower performance of the $\mathrm{Fe}(\mathrm{II}) \mathrm{NHC}$ with respect to $\mathrm{Ru}(\mathrm{II})$ standard. As $\mathrm{Fe}(\mathrm{II})$ regeneration efficiencies were found satisfactory with 
values at least $>80 \%$, we considered other losses originating from the recombination of $\mathrm{TiO}_{2}$ electrons with $\mathrm{I}_{3}{ }^{-}$. Such kind of recombination kinetics, probed by EIS (Figures S37-S419) for Nyquist plots) in the dark at various forward voltages, revealed that the total cell resistance $\left(R_{\text {TOT }}=R_{\Omega}+R_{C T}\right.$, where $R_{\Omega}$ is the constant contact resistance (20-25 $\Omega$ ) and $R_{C T}$ is the charge transfer resistance ascribed to recombination with $\mathrm{I}_{3}{ }^{-}$at the $\mathrm{TiO}_{2}$ /electrolyte interface) varied according to N719 < ARM7 < ARM11 ARM13 $\approx$ C1. As shown in Figure S42, the major differences are observed at the threshold of the dark current process, (i.e. ca. $-0.3 \mathrm{~V}$ ) while the dark response of all sensitized electrodes in contact with el 2 becomes quite aligned when the applied bias becomes more negative than $-0.4 \mathrm{~V}$. These measurements, performed in complete cells, under applied bias provide a more reliable means of estimating the recombination resistance than the spectroscopic observation of electrons in an electrically insulated electrode, like in our previous work, ${ }^{36}$ and show that the recombination between $\mathrm{TiO}_{2}$ electrons and $\mathrm{I}_{3}{ }^{-}$in the el 2 formulation is not a critical issue with respect to $\mathbf{N 7 1 9}$. This, combined with the $\eta_{\text {reg }}$ values from TAS, indicates that the main kinetic limitation of the new $\mathrm{Fe}(\mathrm{II}) \mathrm{NHC}$ sensitizers may still reside in charge injection, partly competitive with excited state deactivation processes. As a comparison we observe that injection is possible also in the absence of high charge density cations, consistent with the strong reducing capabilities of these $\mathrm{Fe}(\mathrm{II}) \mathrm{NHC}$ excited states and with previously discussed TA measurements, but the resulting IPCE is reduced to ca. 5-6\%, associated to a maximum photocurrent density of $0.54 \mathrm{~mA} / \mathrm{cm}^{2}$ (Figure S43)

To address more specifically this point, the IPCE spectra of all $\mathrm{Fe}(\mathrm{II})$ dyes are shown in Figure 8(a): generally these exhibit a photocurrent action spectrum which agrees with their absorption spectrum when contacted by $\mathrm{a} \mathrm{Li}^{+}$and $\mathrm{Mg}^{2+}$ containing electrolyte which causes a bathochromic shift of the absorption, as previously discussed. This is also a direct experimental evidence of the interaction of these cations with the sensitized $\mathrm{TiO}_{2}$ surface. As expected, all dyes show their maximum conversion in correspondence of the their main visible MLCT band which extends from 450 up to $700 \mathrm{~nm}$ and peaks around $500-520 \mathrm{~nm}$, decreasing then sharply when moving to the red, becoming almost negligible at $\lambda>650 \mathrm{~nm}$. The maximum IPCE values range between 30\% (ARM11) and 40\% (ARM13). Consistent with the J/V results, the relatively broad and higher IPCE of ARM13 provides the best photocurrent density under AM 1.5 G illumination. APCE = $\Phi_{\text {inj }} \eta_{\text {reg }}$ reaches in the best cases (ARM13 and C1) the $40 \%$ plateau (Figure $8(\mathbf{b})$ ), which, coupled to an estimate on $\eta_{\text {reg }}$ of $85 \pm 5 \%$ affords (assuming an IPCE error of the order of $1 \%$ ) a quantum yield of charge injection of $47 \pm 4 \%$, which agrees with the previously reported value around $50 \%$ for the C1 dye. $^{36}$
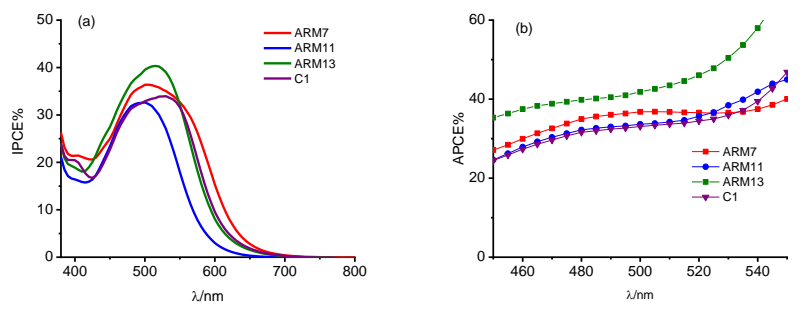

Figure 8: (a), IPCE spectra obtained with e/2 in Fe(II)NHC sensitized cells. (b), APCE curves obtained from Figure 1 . The tendency to diverge at low $\lambda$ is generated by errors in a proper estimation of the optical density of the electrod
when the absorbance decreases sharply from the maximum around $500 \mathrm{~nm}$

We have found for all dyes (Figure S41) a slight improvement in the power conversion efficiencies, when using el3 (obtained by adding 0.1M TBAl to the electrolyte 2). With this electrolyte, the dye which benefited the most was ARM13, whose IPCE and APCE exceeded $40 \%$ (Figure S42) corresponding to a photocurrent of $4.44 \mathrm{~mA} / \mathrm{cm}^{2}$, (Figure 9(a)) which, coupled to a FF of $64 \%$ led to $1.27 \%$ PCE. With the same electrolyte the standards $\mathrm{C} 1$ and $\mathrm{N} 719$ increased from $1.03 \%$ to $1.11 \%$ and from $3.57 \%$ to $3.68 \%$ respectively.


Figure 9: (a) J-V curves obtained with electrolyte 3 under AM 1.5 G illumination (solid lines) and in dark conditions (dashed lines). (b) ARM13 sensitized solar cell equipped with Pt coated FTO counter electrode in the pr
1.5 illumination (solid lines) and in the dark (dashed lines)

When using a partly reflective platinum coated counter electrode, the ARM13 photocurrent increased further to 4.98 $\mathrm{mA} / \mathrm{cm}^{2}$ (Figure $\mathbf{9}(\mathbf{b})$ ) which is the main responsible of the enhancement at $1.44 \%$ power conversion efficiency (Table 3 ). This PCE value represents, to the best of our knowledge, the highest efficiency so far recorded with Fe(II) sensitizers in a DSSC.

Table 3: Photovoltaic parameters of ARM13 compared with C1 with blocking under layer after double annealing Pt cells

\begin{tabular}{cccccc}
\hline Dyes & Electrolyte & $\begin{array}{c}\text { Jsc } \\
\left(\mathrm{mA} / \mathrm{cm}^{2}\right)\end{array}$ & $\begin{array}{c}\text { Voc } \\
(\mathrm{V})\end{array}$ & $\begin{array}{c}\mathrm{FF} \\
(\%)\end{array}$ & $\begin{array}{c}\text { PCE } \\
(\%)\end{array}$ \\
\hline C1 & $e / 2$ & 4.02 & 0.49 & 58 & $1.14 \pm 0.07$ \\
ARM13 & $e / 2$ & 4.26 & 0.51 & 59 & $1.29 \pm 0.09$ \\
ARM13 & $e / 3$ & 4.98 & 0.47 & 62 & $1.44 \pm 0.07$ \\
\hline
\end{tabular}

The role of TBAI is still not fully understood. With Fe(II) sensitizers we could not observe a reduced recombination from the dark currents when in presence of TBAI, contrary to what we record and it is reported with $\mathbf{N 7 1 9}$ (Figures S43), while the transient kinetics (Figure S33 (a) and (b) ), did not reveal, even at our best time resolution an increased regeneration efficiency. The JV curves suggest that overall cell resistance is reduced when TBAI is present and such effect 
could arise from a reduced resistance either at the $\mathrm{TiO}_{2}$ /electrolyte interface, or in the diffusional resistance of the electrolyte. A detailed EIS investigation is currently underway to elucidate this point.

\subsection{Computational analysis}

Here we will try to rationalise the photovoltaic performances of the investigated dyes relying on DFT and TD-DFT calculations of the isolated and $\mathrm{TiO}_{2}$-grafted systems, focusing our attention on the photocurrent generation. To sum up, we have an homoleptic dye, $\mathbf{C 1}$, that, thanks to the presence of $\mathrm{Mg}^{2+}$ cations in the electrolyte, can inject photoexcited electrons into the $\mathrm{TiO}_{2}$ conduction band, yielding photocurrents only slightly lower than the ones of its heteroleptic analogous, ARM13. On its side, ARM13, despite possessing the worst optoelectronic properties among the series (weaker absorption at shorter wavelengths), show the highest efficiency and the highest photocurrent values. Concerning the effect of the conjugated spacer, surprisingly both the heteroleptic dyes, ARM11 and ARM7, even with the correct dye-to-TiO2 charge transfer directionality and good light harvesting properties (Figure 2) underperform ARM13 and even C1. Finally, with reference to the nature of the conjugated spacer, the recorded photocurrents (ARM7>ARM11, Table 3) seem to be coherent with the redshifted absorption spectrum of the thiophene-substituted compound (ARM7). The questions that we need to answer are, therefore, i) which is the effect of $\mathrm{Mg}^{2+}$ at the $\mathrm{C} 1 @ \mathrm{TiO}_{2}$ interface, that allows to have electron injection? ii) Can the presence of $\mathrm{Mg} 2+$ also justify the higher photocurrent value recorded for ARM13-based DSSCs, despite its quite low and slightly blue-shifted absorption spectrum (Figure 2) iii) Why, despite their superior optical properties, the spacersubstituted complexes show lower electron injection efficiencies than ARM13?

\subsubsection{Effect of $\mathrm{MgI}_{2}$ electrolyte}

Following a computational approach similar to the one used by some of us to model the effect of $\mathrm{Li}^{+}$cations at the indoline D102- $\mathrm{TiO}_{2}$ interface, ${ }^{58}$ we have simulated the adsorption of a $\mathrm{Mg}^{2+}$ cation at the $\mathbf{C 1}_{0} @ \mathrm{TiO}_{2}$ and ARM13@TiO 2 interfaces and analysed the interfacial electron transfer kinetics. We are aware that a realistic model of the dye/ $/ \mathrm{TiO}_{2}$ interfaces should include several cations adsorbed on the surface at different positions. Nevertheless, as it has been shown for $\mathrm{Li}^{+58}$ and $\mathrm{H}^{+59}$ cations adsorbed on the $\left(\mathrm{TiO}_{2}\right)_{82}$, there is an almost linear effect as the number of positive charges increases on the energy shift of $\mathrm{TiO}_{2} \mathrm{CB}$ and dye's LUMO levels, as well as on the gain in the injection rates. Thus, since our main target is to examine the qualitative impact of the cation on the dye@ $\mathrm{TiO}_{2}$ electronic structure, we limit ourselves to a single cation model, stably interacting close to the dye's anchoring group. ${ }^{58}$



Figure 10. Optimized structure of the $\mathbf{C} 1 @ \mathbf{M g}-\mathrm{TiO}_{2}$ system; a zoomed image of the $\mathrm{Mg}^{2+}$ cation (green color atom) and its closest $\mathrm{O}$ neighbor atoms is displayed in the onset of the perspective view as well.

As is apparent in Figure 10 for the $\mathbf{C 1}$ dye, the $\mathrm{Mg}^{2+}$ cation lies close to three oxygens of the $\mathrm{TiO}_{2}$ surface in a hollow fashion (distances to the nearest neighbour $\mathrm{O}$ atoms of $\mathrm{TiO}_{2}$ of about $2.0 \AA$, $2.5 \AA$ and $2.4 \AA$ ), as well as to one the anchoring $O$ atoms of the dye (Mg-O distance of $2.3 \AA$ ). As shown by the Projected Density of States (PDOS) plots in Figure 11, the main energetic effect of the presence of the cation at the surface is the expected negative shift for all the unoccupied interfacial energy levels in both $\mathbf{C 1}$ and ARM13-sensitized $\mathrm{TiO}_{2}$. A deeper look at the localization of the frontiers MOs depicted in Figure 12 , however, reveals that the adsorption of $\mathrm{Mg}$ cations on the semiconductor surface in proximity of the dye, induces a striking and more pertinent consequence for $\mathbf{C 1}$ (top panels in Figure 11).

In C1@TiO 2 , indeed, as we know, the dye's LUMO is localized in the unbound ligand with essentially no electronic coupling with the semiconductor CB states (99\% localization on the dye): the metal-to-ligand charge transfer goes in the opposite direction with respect to $\mathrm{TiO}_{2}$ and electron injection is impeded. This is a consequence of the destabilization of the CT toward the deprotonated-anchored ligand. When the $\mathrm{Mg}$ cation is present at the interface, on the other hand, its localized positive charge in proximity of the anchoring unit stabilizes the CT toward the

surface-adsorbed ligand, where the dye's LUMO is now localized (Figure 11): the lowest-energy bright MLCT transition recovers the correct directionality and electron injection is now possible, thus explaining the measured photocurrents. On the other hand, the shape and relative energies for the highest occupied levels of the dyes remain very similar upon $\mathrm{Mg}^{2+}$ adsorption, since their localization on the top and central part of the dye, far from the surface, significantly weakens their interaction with the cation (see Figures S21 and S22). 


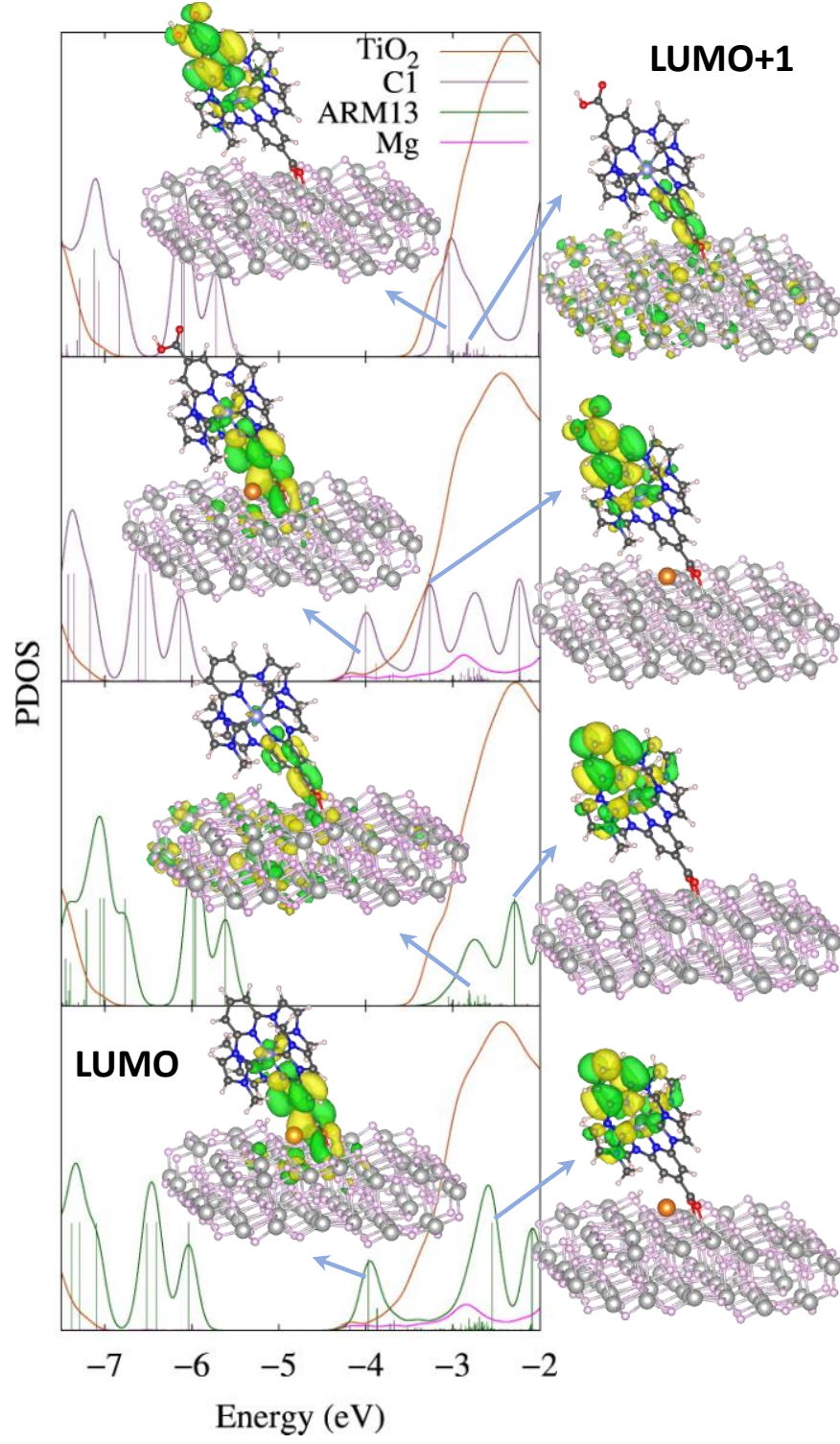

Figure 11. Projected Density of States (PDOS) of the $\mathbf{C} \mathbf{1} @ \mathrm{TiO}_{2} / \mathbf{C} \mathbf{1} @ \mathbf{M g}-\mathbf{T i O} \mathbf{O}_{\mathbf{2}}$ (top) and ARM-13@TiO $/$ /ARM-13@Mg-TiO 2 (bottom) systems over the atoms belonging to the dye (red), $\mathrm{TiO}_{2}$ surface (blue) and $\mathrm{Mg}^{2+}$ cation (magenta) as calculated by Mulliken population analysis. For visualisation purposes, only the vertical bars of the dye's PDOS are represented here and the $\mathrm{TiO}_{2}$ DOS intensity has been divided by a factor of 10 . The isodensity plots (isovalue 0.02 a.u.) of the dye unoccupied MOs indicated by the grey arrows are displayed in the onsets of the PDOS plot.

To extract a more quantitative picture, we calculated the diabatic couplings between the levels of the dyes and the ones of the $\mathrm{TiO}_{2}$ slab, with the aim of evaluating how the $\mathrm{Mg}^{2+}$ cation affects the interfacial electron transfer kinetics (injection/recombination times). The diabatic energy levels for the dye's frontiers molecular orbitals and $\mathrm{TiO}_{2}$ conduction and valence bands are reported in Table S4, while the diabatic electronic couplings are plotted in Figures S23-S26 in Supporting Information. The results relative to the electron injection process, by considering the electronic coupling for both LUMO/LUMO+1 and the CB states are gathered in Table 4 for the C1@TiO,$\quad$ C1@Mg-TiO, ARM13@TiO 2 and ARM13@Mg-TiO 2 systems, while the data for the recombination between the injected electrons $\left(\mathrm{TiO}_{2} \mathrm{VB}\right)$ and the oxidized dye (HOMO/HOMO-1/HOMO-2) are listed in Table S5 in Supporting Information. It is important to stress that the electron transfer efficiency results from the interplay of two factors, the extent of the electronic coupling between the donor's and the acceptor's states and the density of available acceptor's $\left(\mathrm{TiO}_{2}\right)$ states; their product gives the probability distribution $\Gamma(\varepsilon)$, that, evaluated at the energy of the donor state, provides the injection rates. The injection times of 4.6 and 3.9 fs (Table 5) calculated for the LUMO+1 and LUMO in $\mathbf{C 1}_{0} @ \mathrm{TiO}_{2}$ and $\mathrm{C1} @ \mathrm{Mg}-\mathrm{TiO}_{2}$, respectively, clearly show the recovery of the correct CT direction in the homoleptic complex when $\mathrm{Mg}^{2+}$ is at the interface and the possibility of injecting electrons from the LUMO. Moreover, the sizeable increase in the electronic coupling between the LUMO and the surface localized $\mathrm{TiO}_{2} \mathrm{CB}$ edge state (Figures S23 and S25 in Supporting Information) largely compensates the detrimental shift of the dye's LUMO at lower energies, yielding a decrease of $\mathrm{TiO}_{2}$ empty acceptor states (second and fourth panels in Figure 11 starting from the top). Similar considerations apply for ARM13, for which an increase in the injection probability $\Gamma_{\mathrm{L}}$ is calculated when $\mathrm{Mg}^{2+}$ is at the interface and the injection time decreases from 4.3 to $3.7 \mathrm{fs}$. Notably our predicted interfacial electron injection kinetics perfectly match the photocurrent values recorded for $\mathbf{C 1}$ and ARM13 (Table 2), indicating slightly superior injection efficiency for the heteroleptic complex, despite its inferior light harvesting capability (Figure 2). Regarding the recombination rates, as shown by data in Table S5 and Figures S24 and S26 in Supporting Information, the addition of $\mathrm{Mg}^{2+}$ is translated in a slight increase in the couplings of $\mathrm{TiO}_{2}$ the highest occupied levels of the dye. Nevertheless, this increment is not so significant to expect a big change in the recombination rates and the device efficiencies.

Table 4 Probability distributions, $\boldsymbol{\Gamma}\left(\boldsymbol{\varepsilon}_{\mathrm{k}}\right)(\mathrm{eV})$ extracted at the dye's LUMO $\left(\boldsymbol{\Gamma}_{\mathrm{L}}\right)$ and LUMO+1 $\left(\boldsymbol{\Gamma}_{\mathbf{L}+1}\right)$ diabatic energies (Table S4 in Supporting Information) and associated injection times, $\boldsymbol{\tau}(\mathrm{fs})$

\begin{tabular}{|l|r|r|r|r|}
\hline System & \multicolumn{1}{c|}{$\begin{array}{c}\boldsymbol{\Gamma}_{\mathrm{L}} \\
(\mathbf{e V})\end{array}$} & \multicolumn{1}{c|}{$\begin{array}{c}\boldsymbol{\tau}_{\mathrm{L}} \\
(\mathbf{f s})\end{array}$} & \multicolumn{1}{c|}{$\begin{array}{c}\boldsymbol{\Gamma}_{\mathrm{L}+1} \\
(\mathbf{e V})\end{array}$} & \multicolumn{1}{|c|}{$\begin{array}{r}\boldsymbol{\tau}_{\mathrm{L}+\mathbf{1}} \\
(\mathbf{f s})\end{array}$} \\
\hline C1@TiO $_{2}$ & $1.12 \mathrm{E}-05$ & 58530 & 0.142 & 4.6 \\
C1@Mg-TiO $_{2}$ & 0.167 & 3.9 & $7.54 \mathrm{E}-05$ & 8723 \\
ARM13@TiO $_{2}$ & 0.152 & 4.3 & $3.07 \mathrm{E}-05$ & 21428 \\
ARM13@Mg-TiO $_{2}$ & 0.179 & 3.7 & $4.43 \mathrm{E}-05$ & 14840 \\
\hline
\end{tabular}

\subsubsection{Effect of the conjugated spacer}

A fast and reliable way to estimate the electron injection capability of a dye sensitizer is looking at the extent of localization of the LUMO on the anchoring $\mathrm{COOH}$ unit. ${ }^{59}$ Nevertheless, a qualitative evaluation of the spatial localization of holes and electrons in the lowest-energy bright MLCT transitions as it appears the Natural Transition Orbitals 
(NTOs) depicted in Figure S20, although capable to provide a rough idea, is not sufficient.

A more quantitative and accurate analysis of the charge and hole localization characterizing the lowest bright excited state has been obtained here by employing the transition density matrices manipulation tools implemented in TheoDORE. ${ }^{42}$ The calculated percentages are reported in Table S7 in Supporting Information and depicted in Figure 12. The relevant data here are the percentages of electrons localized on the anchoring moiety (COOH): $16.3 \%, 8.3 \%$ and $6.7 \%$ for ARM13, ARM7 and ARM11, respectively. These values directly correlate with the corresponding measured photocurrents of 3.95 (ARM13), 3.55 (ARM7) and $2.69 \mathrm{~mA} / \mathrm{cm}^{2}$ (ARM11) reported in Table 2. It is now evident that, despite inducing an overall improvement of the optical properties, the introduction of a conjugated thiophene or phenyl spacer results in a markedly decreased CT toward the anchoring group, with reduced injection efficiencies. $^{58}$
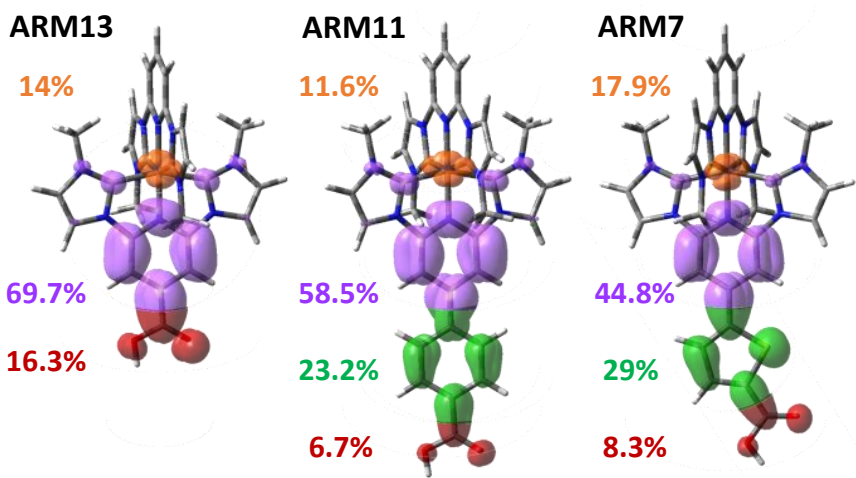

Figure 12. Electron Natural Transition Orbitals (NTOs) in ARM13, ARM11 and ARM7 with the percentages of delocalization for each fragment. The colours employed to plot the isodensities corresponded to the unbound pyridylNHC ligand and iron (orange), anchoring ligand: pyridylNHC (purple), spacer (green
and carboxylic group (red) moieties. The isovalues used for this plot was 0.03 a.u.

Although the presence of $\mathrm{Mg}^{2+}$ cations at the dye/ $/ \mathrm{TiO}_{2}$ interface will increase the localization on the anchoring unit and thus the coupling with the CB states as shown for ARM13, we do not expect a differential effect within the series and thus a change in the order of the predicted photocurrents.

\section{Conclusion}

This work represents an important step forward to the development of more efficient Iron-carbene dyes sensitizers: we report here a record power conversion efficiency of $1.44 \%$, never recorded for a Fe-sensitized DSSC. This is the successful result of the knowledge we acquired in the last years on the chemical design rules required to improve the dye-to- $\mathrm{TiO}_{2}$ electron injection, ${ }^{30}$ as well as on the optimization of electrolyte composition and cell fabrication. ${ }^{36}$ In our previous studies, indeed, we showed that even if the homoleptic Fecarbene complex, C1, does not possess the correct charge transfer direction in its lowest-energy excited state, the use of the $\mathrm{Mgl}_{2}$ electrolyte can notably improve the interfacial charge generation, increasing the overall power conversion efficiency from $0.13 \%{ }^{30}$ to $1 \% .{ }^{36}$ Here we, therefore, moved to the design of heteroleptic complexes, for which the lowest-energy MLCT state has the desired topology and we used $\mathrm{Mg}^{2+}$-based electrolytes with the aim of further improving the photovoltaic performances. More specifically, we have prepared three heteroleptic complexes: ARM13, being the analogous of C1, ARM11 and ARM7, having, respectively, a thiophene and a phenyl spacer between the iron centre and the carboxylic anchoring group, introduced to increase the metal to surface charge separation and avoid undesired recombination processes. We also included in the series the original homoleptic complex, $\mathbf{C 1} \mathbf{1}^{30,36}$ which served as a reference to interpret the effects induced by the structural changes.

We obtained power conversion efficiencies in the order ARM13>C1 >ARM7>ARM11, with the record value of $1.44 \%$ for ARM13. By comparing recombination and regeneration kinetics we obtained a $\eta_{\text {reg }}$ close to $80-90 \%$ that combined with APCE\% revealed the main limitation in charge injection due to a competition with the excited state deactivation that occurs in the sub ns range, while the dark current is quite comparable with that of some of the best $\mathrm{Ru}(\mathrm{II})$ reference dyes .

Based on computational modelling of the C1/ARM13@TiO interface and accurate calculations of the electron injection/recombination kinetics we shown that the presence of $\mathrm{Mg}^{2+}$ cations adsorbed at the dye/ $/ \mathrm{TiO}_{2}$ interface stabilizes the $\mathrm{CT}$ toward the surface-adsorbed carbene ligand allowing for a quite efficient electron injection in the case of the homoleptic complex $\mathbf{C 1}$ and for an improved injection rate in the case of the heteroleptic ARM-13. Moreover, concerning the effect of the conjugated spacer, despite a larger absorption in the UV-Vis region and similar energetic alignments with respect to ARM13, the ARM7 and ARM11 yielded lower device performances. The reason behind this phenomenon is the local $\pi-\pi^{*}$ character of the MLCT excitations introduced by the aromatic spacers, which significantly lowers the charge separation within the dye and the injection of electrons into the semiconductor.

Here we demonstrate that, combining a rational molecular design, driven by reliable quantum chemical simulations, with an accurate experimental characterization of the efficiency of the interfacial electron transfer processes, allowing for electrolyte and device optimization, one can effectively boost the performances of Iron-based DSSCs.

\section{Conflicts of interest}

There are no conflicts to declare.

\section{Acknowledgements}

The L2CM thanks the French Agence Nationale de Recherche (ANR-16-CE07-0013-02) and LUE (IMPACT N4S) for funding and grants to A.R.M. The L2CM laboratory is grateful to F. Dupire for mass spectrometry of the complexes. V.D.-C. acknowledges financial support through the COMETE project (COnception in 
silico de Matériaux pour l'EnvironnemenT et l'Energie) cofunded by the European Union under the program 'FEDER-FSE Lorraine et Massif des Vosges 2014-2020. HPC resources from HPC resources from GENCI-CCRT/CINES (Grants 2018A0010810139) and LPCT local computational resources are also acknowledged. E. M. thanks the Fondo Sociale europeo Programma Operativo (2014-2020) Regione Emilia Romagna for a grant.

\section{Notes and references}

1 B. O'Regan and M. Grätzel, Nature, 1991, 353, 737-740.

2 M. Grätzel, Prog Photovolt Res Appl, 2000, 8, 171-185.

3 M. Grätzel, Nature, 2001, 414, 338-344.

4 M. K. Nazeeruddin, A. Kay, I. Rodicio, R. Humphry-Baker, E. Mueller, P. Liska, N. Vlachopoulos and M. Graetzel, J. Am. Chem. Soc., 1993, 115, 6382-6390.

5 A. S. Polo, M. K. Itokazu and N. Y. Murakami Iha, Coord. Chem. Rev., 2004, 248, 1343-1361.

6 Md. K. Nazeeruddin, S. M. Zakeeruddin, J.-J. Lagref, P. Liska, P. Comte, C. Barolo, G. Viscardi, K. Schenk and M. Graetzel, Coord. Chem. Rev., 2004, 248, 1317-1328.

7 K. C. D. Robson, P. G. Bomben and C. P. Berlinguette, Dalton Trans., 2012, 41, 7814.

8 M. Chandrasekharam, M. A. Reddy, S. P. Singh, B. Priyanka, K. Bhanuprakash, M. L. Kantam, A. Islam and L. Han, J. Mater. Chem., 2012, 22, 18757.

9 Y. Chi, B. Tong and P.-T. Chou, Coord. Chem. Rev., 2014, 281, 125.

10 M. G. Lobello, K.-L. Wu, M. A. Reddy, G. Marotta, M. Grätzel, M. K. Nazeeruddin, Y. Chi, M. Chandrasekharam, G. Vitillaro and F. De Angelis, Dalton Trans, 2014, 43, 2726-2732.

11 W.-C. Chen, F.-T. Kong, R. Ghadari, Z.-Q. Li, F.-L. Guo, X.-P. Liu, Y. Huang, T. Yu, T. Hayat and S.-Y. Dai, J. Power Sources, 2017, 346, 71-79.

12 S. Mathew, A. Yella, P. Gao, R. Humphry-Baker, B. F. E. Curchod, N. Ashari-Astani, I. Tavernelli, U. Rothlisberger, Md. K. Nazeeruddin and M. Grätzel, Nat. Chem., 2014, 6, 242-247.

13 S. Ardo and G. J. Meyer, Chem Soc Rev, 2009, 38, 115-164.

14 A. Listorti, C. Creager, P. Sommeling, J. Kroon, E. Palomares, A. Fornelli, B. Breen, P. R. F. Barnes, J. R. Durrant, C. Law and B. O’Regan, Energy Environ. Sci., 2011, 4, 3494.

15 A. Listorti, B. O'Regan and J. R. Durrant, Chem. Mater., 2011, 23, 3381-3399.

16 C. E. Housecroft and E. C. Constable, Chem. Soc. Rev., 2015, 44, 8386-8398.

17 M. Sandroni, Y. Pellegrin and F. Odobel, Comptes Rendus Chim., 2016, 19, 79-93.

18 A. Mishra, M. K. R. Fischer and P. Bäuerle, Angew. Chem. Int. Ed., 2009, 48, 2474-2499.

19 W. Zeng, Y. Cao, Y. Bai, Y. Wang, Y. Shi, M. Zhang, F. Wang, C. Pan and P. Wang, Chem. Mater., 2010, 22, 1915-1925.

20 L. Zhang, X. Yang, W. Wang, G. G. Gurzadyan, J. Li, X. Li, J. An, Z. $\mathrm{Yu}, \mathrm{H}$. Wang, B. Cai, A. Hagfeldt and L. Sun, ACS Energy Lett., 2019, 4, 943-951.

21 S. Ferrere and B. A. Gregg, J. Am. Chem. Soc., 1998, 120, 843844.

22 S. Ferrere, Chem. Mater., 2000, 12, 1083-1089.

23 C. R. Tichnell, J. N. Miller, C. Liu, S. Mukherjee, E. Jakubikova and J. K. McCusker, J. Phys. Chem. C, 2020, 124, 1794-1811.
24 E. A. Juban, A. L. Smeigh, J. E. Monat and J. K. McCusker, Coord. Chem. Rev., 2006, 250, 1783-1791.

25 Y. Liu, T. Harlang, S. E. Canton, P. Chábera, K. Suárez-Alcántara, A. Fleckhaus, D. A. Vithanage, E. Göransson, A. Corani, R. Lomoth, V. Sundström and K. Wärnmark, Chem. Commun., 2013, 49, 6412.

26 T. Duchanois, T. Etienne, C. Cebrián, L. Liu, A. Monari, M. Beley, X. Assfeld, S. Haacke and P. C. Gros, Eur. J. Inorg. Chem., 2015, 2015, 2469-2477.

27 T. C. B. Harlang, Y. Liu, O. Gordivska, L. A. Fredin, C. S. Ponseca, P. Huang, P. Chábera, K. S. Kjaer, H. Mateos, J. Uhlig, R. Lomoth, R. Wallenberg, S. Styring, P. Persson, V. Sundström and K. Wärnmark, Nat. Chem., 2015, 7, 883-889.

28 L. Liu, T. Duchanois, T. Etienne, A. Monari, M. Beley, X. Assfeld, S. Haacke and P. C. Gros, Phys Chem Chem Phys, 2016, 18, 12550-12556.

29 Y. Liu, P. Persson, V. Sundström and K. Wärnmark, Acc. Chem. Res., 2016, 49, 1477-1485.

30 M. Pastore, T. Duchanois, L. Liu, A. Monari, X. Assfeld, S. Haacke and P. C. Gros, Phys Chem Chem Phys, 2016, 18, 28069-28081.

31 T. Duchanois, L. Liu, M. Pastore, A. Monari, C. Cebrián, Y. Trolez, M. Darari, K. Magra, A. Francés-Monerris, E. Domenichini, M. Beley, X. Assfeld, S. Haacke and P. Gros, Inorganics, 2018, 6, 63.

32 A. Francés-Monerris, K. Magra, M. Darari, C. Cebrián, M. Beley, E. Domenichini, S. Haacke, M. Pastore, X. Assfeld, P. C. Gros and A. Monari, Inorg. Chem., 2018, 57, 10431-10441.

33 K. Magra, E. Domenichini, A. Francés-Monerris, C. Cebrián, M. Beley, M. Darari, M. Pastore, A. Monari, X. Assfeld, S. Haacke and P. C. Gros, Inorg. Chem., 2019, 58, 5069-5081.

34 K. Magra, M. Darari, E. Domenichini, A. Francés-Monerris, C. Cebrián, M. Beley, M. Pastore, A. Monari, X. Assfeld, S. Haacke and P. C. Gros, J. Phys. Chem. C, 2020, 124, 18379-18389.

35 K. S. Kjær, N. Kaul, O. Prakash, P. Chábera, N. W. Rosemann, A. Honarfar, O. Gordivska, L. A. Fredin, K.-E. Bergquist, L. Häggström, T. Ericsson, L. Lindh, A. Yartsev, S. Styring, P. Huang, J. Uhlig, J. Bendix, D. Strand, V. Sundström, P. Persson, R. Lomoth and K. Wärnmark, Science, 2019, 363, 249-253.

36 E. Marchini, M. Darari, L. Lazzarin, R. Boaretto, R. Argazzi, C. A. Bignozzi, P. C. Gros and S. Caramori, Chem. Commun., 2020, 56, 543-546.

37 M. Reiher, O. Salomon and B. Artur Hess, Theor. Chem. Acc. Theory Comput. Model. Theor. Chim. Acta, 2001, 107, 48-55.

38 L. A. Fredin, M. Pápai, E. Rozsályi, G. Vankó, K. Wärnmark, V. Sundström and P. Persson, J. Phys. Chem. Lett., 2014, 5, 20662071.

39 I. M. Dixon, F. Alary, M. Boggio-Pasqua and J.-L. Heully, Dalton Trans., 2015, 44, 13498-13503.

40 K. P. Kepp, Inorg. Chem., 2016, 55, 2717-2727.

41 J. Tomasi, B. Mennucci and R. Cammi, Chem. Rev., 2005, 105, 2999-3094.

42 F. Plasser, TheoDORE: a Toolbox for a Detailed and Automated Analysis of Electronic Excited State Computations, 2019.

43 M. J. Frisch, G. W. Trucks, H. B. Schlegel, G. E. Scuseria, M. A. Robb, J. R. Cheeseman, G. Scalmani, V. Barone, B. Mennucci, G. A. Petersson, H. Nakatsuji, M. Caricato, X. Li, H. P. Hratchian, A. F. Izmaylov, J. Bloino, G. Zheng, J. L. Sonnenberg, M. Hada, M. Ehara, K. Toyota, R. Fukuda, J. Hasegawa, M. Ishida, T. Nakajima, Y. Honda, O. Kitao, H. Nakai, T. Vreven, Jr. Montgomery J. A., J. E. Peralta, F. Ogliaro, M. Bearpark, J. J. Heyd, E. Brothers, K. N. Kudin, V. N. Staroverov, R. Kobayashi, J. Normand, K. Raghavachari, A. Rendell, J. C. Burant, S. S. Iyengar, J. Tomasi, M. Cossi, N. Rega, N. J. Millam, M. Klene, J. E. Knox, J. B. Cross, V. 
Bakken, C. Adamo, J. Jaramillo, R. Gomperts, R. E. Stratmann, O. Yazyev, A. J. Austin, R. Cammi, C. Pomelli, J. W. Ochterski, R. L. Martin, K. Morokuma, V. G. Zakrzewski, G. A. Voth, P. Salvador, J. J. Dannenberg, S. Dapprich, A. D. Daniels, Ö. Farkas, J. B. Foresman, J. V. Ortiz, J. Cioslowski and D. J. Fox, Gaussian 09, Gaussian, Inc., Wallingford CT, 2009.

44 M. Pastore, S. Fantacci and F. De Angelis, J. Phys. Chem. C, 2013, 117, 3685-3700.

45 M. Pastore and F. De Angelis, J. Am. Chem. Soc., 2015, 137, 5798-5809.

46 M. Pastore, A. Selloni, S. Fantacci and F. De Angelis, in First Principles Approaches to Spectroscopic Properties of Complex Materials, eds. C. Di Valentin, S. Botti and M. Cococcioni, Springer Berlin Heidelberg, Berlin, Heidelberg, 2014, vol. 347, pp. 1-45.

47 A. Klamt and G. Schüürmann, J Chem Soc Perkin Trans 2, 1993, 799-805.

48 S. Grimme, J. Antony, S. Ehrlich and H. Krieg, J. Chem. Phys., 2010, 132, 154104.

49 G. te Velde, F. M. Bickelhaupt, E. J. Baerends, C. Fonseca Guerra, S. J. A. van Gisbergen, J. G. Snijders and T. Ziegler, J. Comput. Chem., 2001, 22, 931-967.

50 I. Kondov, M. Čížek, C. Benesch, H. Wang and M. Thoss, J. Phys. Chem. C, 2007, 111, 11970-11981.

51 T. Duchanois, T. Etienne, M. Beley, X. Assfeld, E. A. Perpète, A. Monari and P. C. Gros, Eur. J. Inorg. Chem., 2014, 2014, 37473753.

52 A. Francés-Monerris, P. C. Gros, M. Pastore, X. Assfeld and A. Monari, Theor. Chem. Acc., 2019, 138, 86.

53 A. Hagfeldt, G. Boschloo, L. Sun, L. Kloo and H. Pettersson, Chem. Rev., 2010, 110, 6595-6663.

54 S. Ardo, Y. Sun, A. Staniszewski, F. N. Castellano and G. J. Meyer, J. Am. Chem. Soc., 2010, 132, 6696-6709.

55 J. R. Durrant, S. A. Haque and E. Palomares, Coord. Chem. Rev., 2004, 248, 1247-1257.

56 J. N. Clifford, E. Palomares, Md. K. Nazeeruddin, M. Grätzel, J. Nelson, X. Li, N. J. Long and J. R. Durrant, J. Am. Chem. Soc., 2004, 126, 5225-5233.

57 S. Kambe, S. Nakade, T. Kitamura, Y. Wada, S. Yanagida, J. Phys. Chem. B 2002, 106, 2967-2972.

58 S. Agrawal, T. Leijtens, E. Ronca, M. Pastore, H. Snaith and F. De Angelis, J. Mater. Chem. A, 2013, 1, 14675.

59 E. Ronca, G. Marotta, M. Pastore and F. De Angelis, J. Phys. Chem. C, 2014, 118, 16927-16940. 